Materials Science and Engineering Laboratory

\title{
REFERENCE
}

NIST

PUBLICATIONS

NAS-NRC

Assessment Panel

February 13-14, 1992

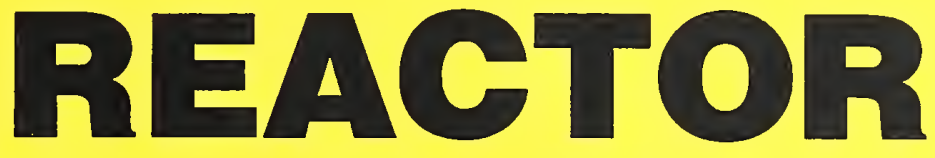

RADIATION

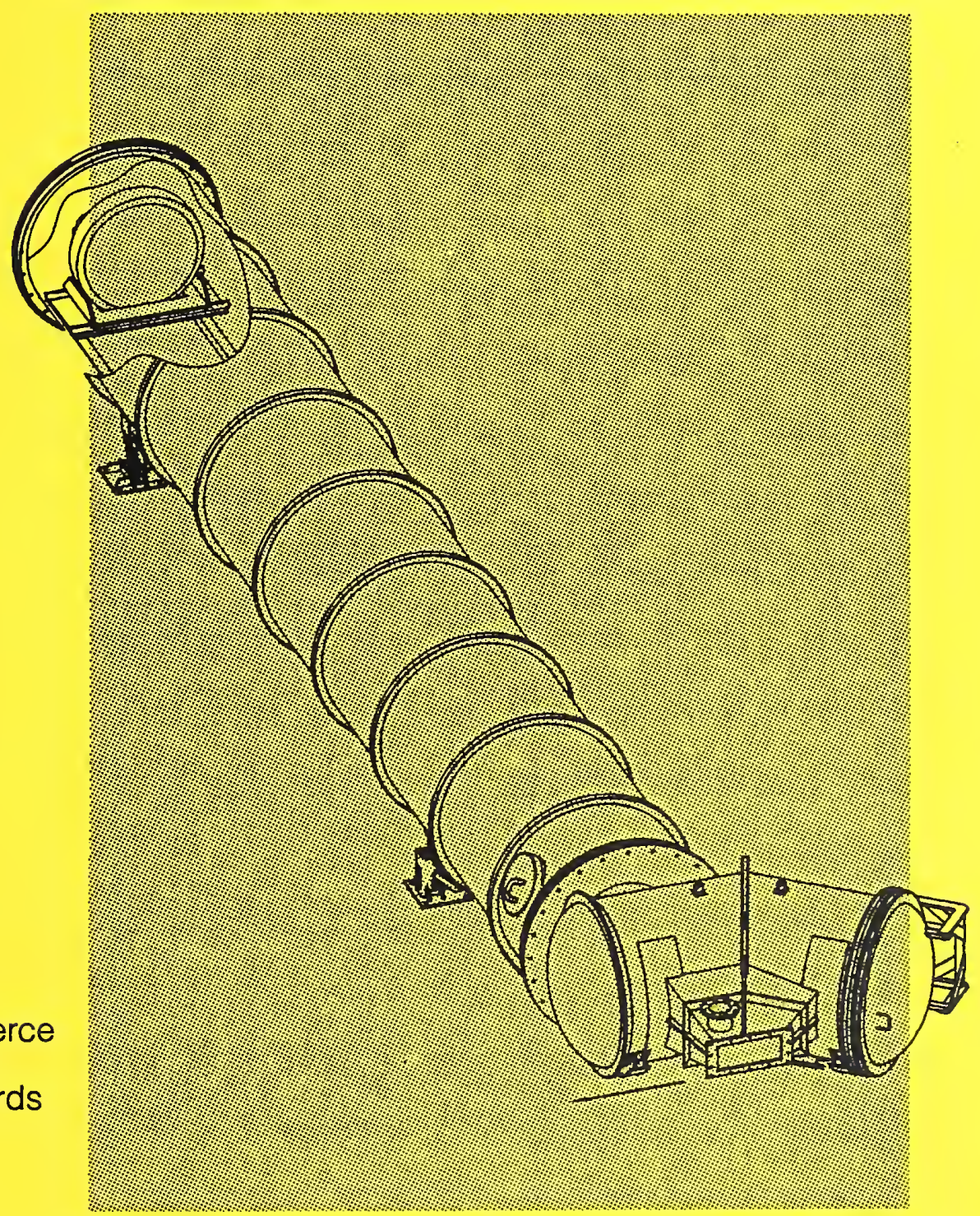

Technical Activities 1991
NISTIR 4698

U.S. Department of Commerce Technology Administration National Institute of Standards and Technology

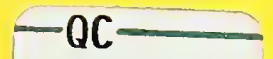

100

.056 
The post-sample flight path/detector housing for the $30 \mathrm{~m}$ NIST/EXXON/ University of Minnesota Small-angle Neutron Scattering Spectrometer at the Cold Neutron Research Facility. 
Materials Science and Engineering Laboratory

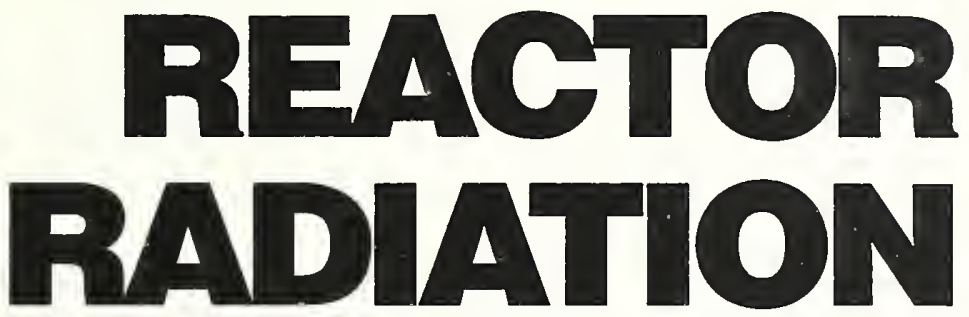

J.M. Rowe, Chief

T.M. Raby, Deputy

NAS-NRC

Assessment Panel

February 13-14, 1992

NISTIR 4698

U.S. Department of Commerce

Technology Administration

National Institute of Standards

and Technology

\section{Technical Activities 1991}

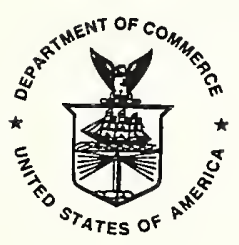

U.S. DEPARTMENT OF COMMERCE, Robert A. Mosbacher,Secretary Technology Administration, Robert M. White, Under Secretary National Institute of Standards and Technology, John W. Lyons, Director 


\begin{abstract}
This report summarizes all those programs which depend on the NIST reactor. It covers the period from October 1, 1990 through September 30, 1991. The programs include the application of neutron methods to the characterization of materials, neutron standards, trace analysis by neutron activation analysis, neutron depth profiling, nondestructive evaluation and the production of radioisotopes.
\end{abstract}

Key words: activation analysis; crystal structure; diffraction; isotopes; molecular dynamics; neutron; neutron radiography; nondestructive evaluation; nuclear reactor; radiation.

\title{
DISCLAIMER
}

Certain trade names and company products are identified to adequately specify the experimental procedure. In no case does such identification imply recommendation or endorsement by the National Institute of Standards and Technology, nor does it imply that the products are necessarily the best available for the purpose. 


\section{CONTENTS}

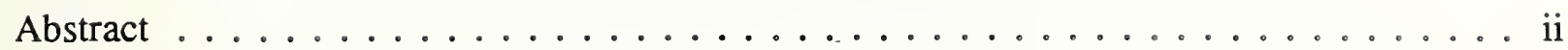

Reactor Radiation Division $\ldots \ldots \ldots \ldots \ldots \ldots \ldots \ldots \ldots \ldots$

Organization Charts $\ldots \ldots \ldots \ldots \ldots \ldots \ldots \ldots \ldots \ldots \ldots \ldots$

Research, Engineering, and Technical Staff . . . . . . . . . . . . 10

Description of Technical Activities .................... 15

Reactor Operations and Services $\ldots \ldots \ldots \ldots \ldots \ldots$

Neutron Condensed Matter Science . . . . . . . . . . . . . . 17

Cold Neutron Project . . . . . . . . . . . . . . . . . . . 31

Independent Programs $\ldots \ldots \ldots \ldots \ldots \ldots \ldots \ldots \ldots \ldots$

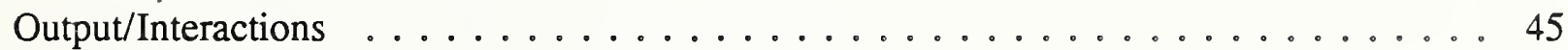

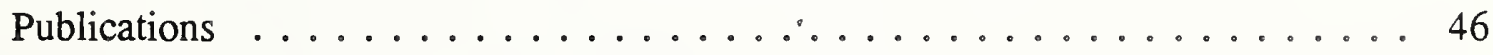

Technical and Professional Committee

Participation and Leadership .................... 55

Industrial and Academic Interactions $\ldots \ldots \ldots \ldots \ldots$

Associated Activities . . . . . . . . . . . . . . . . . . 59 


\title{
REACTOR RADIATION DIVISION (856)
}

\author{
J. Michael Rowe, Chief \\ Tawfik M. Raby, Deputy Chief
}

The responsibilities of the Reactor Radiation Division are threefold: to operate the research reactor (NBSR) as a NIST and national resource in a cost-effective manner while protecting the public safety; to conduct a program of materials research using neutron methods, while developing and maintaining state-of-the-art instrumentation to ensure the best utilization of the NBSR neutron scattering facilities; and to develop and operate the Cold Neutron Research Facility (CNRF) as a National center, providing unique measurement capabilities to U.S. researchers.

In order to fulfill these responsibilities, the Reactor Radiation Division (RRD), in collaboration with researchers in the Materials Science and Engineering Laboratory (MSEL), the Physics Laboratory (PL), the Chemical Science and Technology Laboratory (CSTL), the Electronics and Engineering Laboratory (EEL), and other NIST organizations, as well as many outside organizations (industrial, other government agency, and university), develops and applies neutron methods to a broad range of problems of national concern. The techniques include nuclear methods for chemical analysis, neutron diffraction and scattering for the characterization of microstructure and dynamics of materials (e.g., hydrogen in metals, polymers, layered materials, surfaces and interfaces, ceramics, alloys, amorphous materials, micelles, microporous materials, and buckminsterfullerene), neutron diffraction methods for determination of residual stress and texture, neutron radiography for the non-destructive examination of large components, neutron autoradiography for art history and restoration, and various techniques for neutron flux calibrations and personnel radiation monitoring.

The sections that follow are a summary of the technical activities of the Reactor Radiation Division over the past year. A detailed report on work performed at the NIST reactor is available in a NIST Technical Note entitled "NIST Reactor: Summary of Activities July 1990 through June 1991".

\section{Major Activities:}

The Reactor Operations and Engineering group is primarily responsible for the safe and efficient operation of the reactor in order to provide a cost-effective basis for a unique national resource. In addition, they perform sample irradiations (for both activation analysis and isotope production), help users to design and install new experiments, and are responsible for monitoring many experimental systems (e.g. the helium refrigerator for cold source cooling). This group performs periodic maintenance, completes necessary surveillance tests, designs and oversees major reactor improvements and upgrades, and is responsible for ensuring compliance with all regulatory requirements.

The Neutron Condensed Matter Science group, in collaboration with researchers from MSEL, NIST, other government agencies, universities and industry, carries out an active program of research, applying neutron methods to a broad variety of problems in the general area of materials characterization, with special emphasis on new materials of interest to science and 
technology, such as polymer blends, fullerenes, oxide superconductors, ceramics, chemical catalysts, novel magnetic systems, thin films and interfaces, biological materials, and composites. They also apply neutron methods to non-destructive testing, in areas such as residual stress determination, texture measurements, and neutron radiography. This work involves more than 300 researchers from outside the division, working both collaboratively and independently. In order to maintain the NBSR at the forefront of neutron research, the group also develops new methods, applications, and instrumentation.

The Cold Neutron Project group has responsibility for the development of the Cold Neutron Research Facility (CNRF) as a national resource to provide cold neutron measurement capability to a broad research and development community, including materials science, physics, chemistry, and biology, which is drawn from industry, universities, and government agencies. They are responsible for the development, operation, and maintenance of a new cold neutron source, a network of seven neutron guides, fifteen experimental stations, and a full complement of ancillary equipment such as cryostats, furnaces, and magnets. The CNRF, as a national facility, provides measurement capability to outside researchers, on the basis of scientific or technological merit, and the RRD staff support these researchers, as well as maintaining a NIST research program. Many groups from outside the division are participants in the CNRF, including the Physics (PL), Chemical Science and Technology (CSTL) Laboratories, Exxon Research and Engineering Company, IBM, Eastman Kodak, the Center for Interfacial Engineering, the National Science Foundation, Sandia National Laboratory, the University of Minnesota, the University of Maryland, the University of Missouri, and others.

There are a number of Independent Programs based at the NIST reactor. These programs are long term, make use of the unique capabilities of the NBSR, and are performed in a noncollaborative mode. The Nuclear Methods group (CSTL) develops and applies nuclear methods to problems in analytical chemistry. This group is responsible for much of the activation analysis work performed at the NBSR, including characterization of SRM's, environmental studies, and other areas. They interact strongly with outside users, such as the EPA, FDA, Smithsonian, FBI, and Treasury, and are responsible for the development of the depth profiling, prompt gamma activation analysis and focussed neutron stations in the CNRF. The Neutron Standards and Dosimetry group (PL) carries out a program in radiation standards and calibration, in cooperation with a number of outside organizations, such as the NRC, Westinghouse, and EPRI. This group is also responsible for the development, operation, and maintenance of the fundamental physics and neutron interferometry stations in the CNRF. Other groups include the Smithsonian Institution, the U.S. army, FDA, and the University of Maryland. This year, for the first time, there is an independent program based in MSEL, from the Polymers Division, which utilizes the $8 \mathrm{~m}$ SANS for studies of polymer blends.

Reactor Utilization:

The NBSR is a National Center providing neutron measurement capabilities to researchers in MSEL, NIST and many other government agencies, industries and universities all over the United States. Interactions with other scientists and organizations take the form of both collaborative efforts and independent programs which rely on utilization of the reactor and facilities provided by the NBSR staff. The extent of such interactions for FY 91 are indicated 
in the tables below. The number of personnel shown in Tables 1 and 2 include many short-term collaborators as well as permanent government, university, or industrial guest scientists. These numbers are constantly changing but are believed to be reasonably accurate.

Collaborative interactions are those in which workers from outside the RRD cooperate scientifically with RRD scientists on problems of mutual interest. These interactions are summarized in Table 1.

Many of the other agency, university, and industrial collaborators have worked with us regularly for many years. In many cases research participants provide research sample preparation or characterization, theoretical analysis or other special expertise to the neutron research activities. Most come from all over the world to spend a few days, weeks, or months to carry out specific experiments using the facilities available at the NBSR. Collaborative programs include measurements on new magnetic materials and superconductors, fast-ion conductors, polymers and biological molecules, thin films, catalytic and microporous materials, hydrogen in metals, voids and precipitates in alloys and ceramics, etc.

\section{Table 1. Collaborative Interactions}

\section{No. of Personnel}

\section{FY 91}

RRD Permanent Scientists

Non-RRD Participants

Other NIST

Other Agency

University

Industrial

International

Total Non-RRD

\section{3}

30

53

185

70

$\underline{83}$

Independent programs are those programs carried out by other NIST Divisions and outside organizations without the participation of the RRD scientific staff. Table 2 summarizes these interactions. 
Table 2. Independent Programs

No. of Personnel

FY 91

\begin{tabular}{lr} 
Other NIST & 41 \\
Other Agency & 38 \\
Universities & 41 \\
Industrial & 17 \\
International & $\underline{32}$ \\
\multicolumn{1}{c}{ Total } & 169
\end{tabular}

The outside participants represented in Tables 1 and 2 come from 14 NIST Divisions and offices, 20 other Federal organizations, 63 U.S. universities, 32 U.S. industrial laboratories, and 50 foreign laboratories. 


\section{$\underline{\text { Representative Accomplishments }}$}

- $\quad$ Neutron scattering group scientists have completed the first neutron elastic and inelastic scattering research on buckminsterfullerene $\left(\mathrm{C}_{60}\right)$ worldwide. This work has established the character of the orientational disorder and dynamics in both low temperature and high temperature phases and has shed important light on the nature of the phase transition and the details of the intramolecular forces in this new molecular architecture.

- The NIST/Exxon/U. of Minnesota 30-m SANS was formally dedicated in May 1991. This new facility provides U.S. researchers with capabilities never before available in this country.

- Using the thermal neutron reflectometer, neutron scattering group scientists, in collaboration with researchers from the University of Massachusetts and the University of Pennsylvania, have demonstrated that a dissolved polymer, in this case carboxylic acid terminated polystyrene, forms a weakly stretched "brush" with a parabolic concentration profile when adsorbed on a silicon surface. This fundamental experiment confirms theoretical predictions and is important for understanding the interaction of polymer molecules with surfaces.

- The increased resolution and intensity provided by the 30-m SANS has been used for extensive studies of "superanomalous" flow of suspensions under shear. These new studies are concentrated on a determination of the influence of process variables such as shear rate, temperature and $\mathrm{pH}$.

- Collaborative research with MIT, U. of Maryland and Brookhaven National Laboratory has provided important new evidence for the role of magnetic interactions in the pairing mechanism for high $T_{c}$ superconductivity and for the role of phonons in the mechanism for 2-1-4 "electron" superconductors.

- A two-day workshop on high resolution neutron spectroscopy was held in June, 1991. Over 130 researchers attended to assist NIST planning for this part of the CNRF.

- Computer programs have been written that apply fast Fourier transform techniques to the computation of maximum entropy electron density maps from $\mathrm{x}$-ray diffraction data from macromolecular crystals, exploiting the symmetry of the space groups in which more than $85 \%$ of protein structures are found. These programs have been used to produce a map of the unknown structure of bovine heart creative kinase that clearly shows common features of protein secondary structure.

- $\quad$ RRD scientists, working with two small U.S. companies, have developed a new coating technique ("supermirror" coatings) for neutron guide tubes. This technology is now ready for large-scale production. 
- In our efforts to develop improved refinement methods for quantitative assessment of impurity phases in high $\mathrm{T}_{\mathrm{c}}$ materials, we have recently demonstrated the ability to detect key impurities (e.g. $\mathrm{CuO}$ ) in bulk samples down to less than 0.5 weight $\%$.

- In our Crystal Data Program, the On-Line Search System has been greatly augmented to include new search and analysis tools, additional indexed parameters, and new data. With data on over 170,000 materials, the System is widely used by the industrial community in materials research, in compound identification, and for statistical studies on the solid state.

- The first stage of an experiment to measure the lifetime of the neutron is now being performed by the Physics Laboratory using the NG- 6 beam at the CNRF. In this phase of the experiment, two independent methods for absolute neutron flux measurement are being developed and intercompared. The results of this work will have direct implications for NIST standards and calibration work, as well as providing a needed development for the lifetime work.

- Three new plate-type heat exchangers for the main reactor cooling system have been ordered for delivery by June 1992 . These will replace the two existing heat exchangers and provide one spare for future use, at a total cost that is $\$ 300 \mathrm{~K}$ less than two of the old style heat exchangers.

- The new stage $\mathrm{V}$ fuel elements, which have a heavier loading, are now being introduced into the reactor. These elements will further increase the efficiency of fuel utilization for the NBSR, reducing fuel cycle costs for fabrication, reprocessing, and shipping. 
Organization Chart and Research Staff 


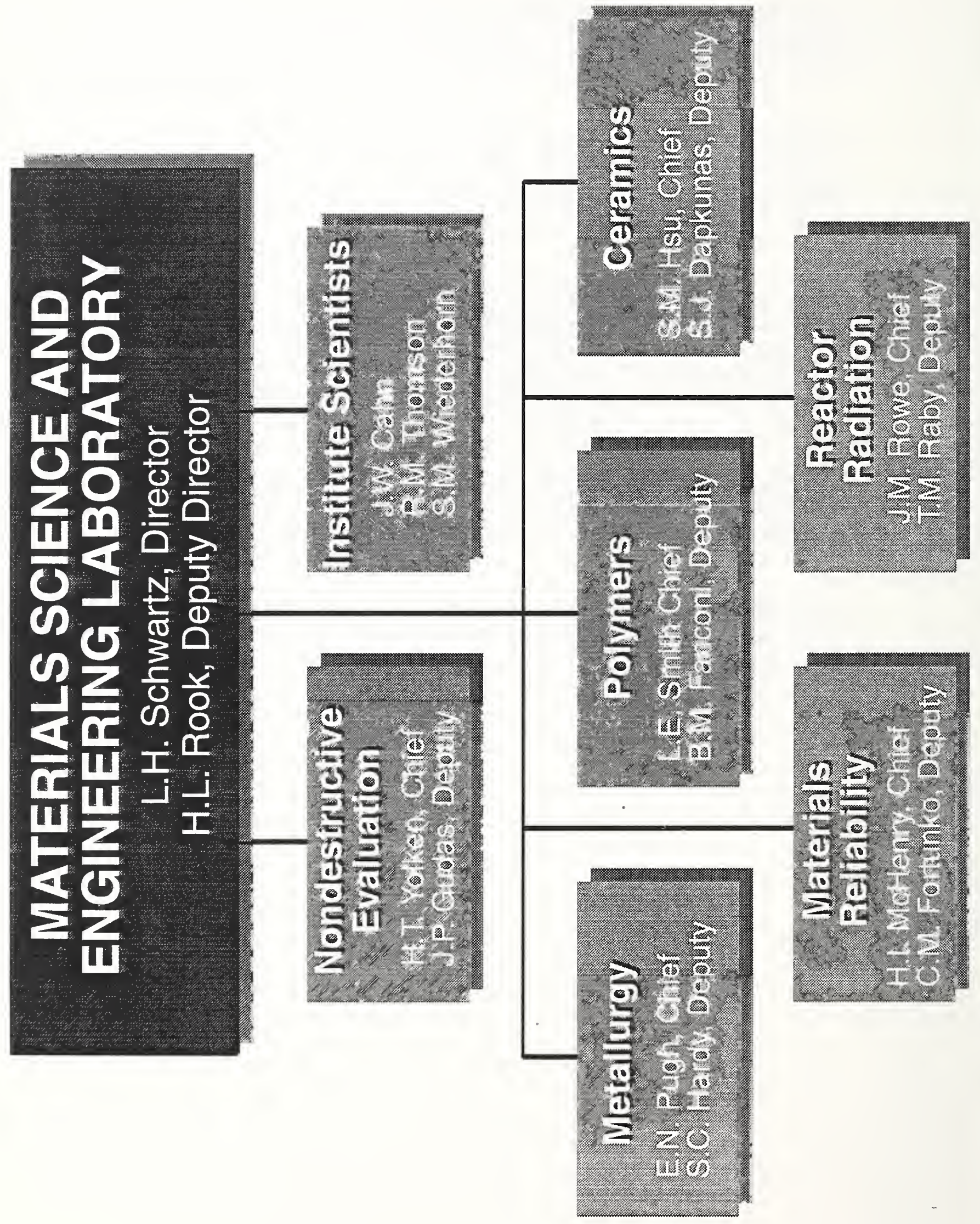




\section{REACTOR RADIATION DIVISION}

J. M. Rowe, Chief

T. M. Raby, Deputy

H. J. Prask, Sci. Asst.

J. M. Hill, Sec.

E. C. Maxwell, Admin. Officer

REACTOR OPERATIONS \& ENGINEERING

T. M. Raby, Chief

J. F. Torrence, Deputy

J. H. Nicklas, Chief Eng.

D. D. Wilkinson, Sec.

C. M. Sweeney, Sec.
S. L. Neal, Admin. Asst. 


\section{RESEARCH AND ENGINEERING STAFF}

J. F. Ankner o Condensed matter physics

- Neutron reflectometry and grazing-angle diffraction

- Instrument development

J. G. Barker o SANS instrumentation and research

N. F. Berk o Condensed matter theory

- SANS theory for microstructure analysis

- Computer software for graphics and data analysis

J. A. Borchers o Thin-film analysis

- Artificially modulated materials

o Magnetism

R. C. Casella o Condensed matter theory, including high $T_{c}$

o Group theory analyses of neutron scattering from condensed matter

o Fundamental physics, especially as related to reactor experiments

R. S. Conway o Electronics engineering

o Nuclear instrumentation

J. R. D. Copley o Condensed matter physics

o Time-of-flight spectrometer development

- Neutron instrumentation conceptual design

W. E. Dickerson o Neutron scattering instrumentation

- Microcomputer interfacing

- Nuclear and engineering physics

R. W. Erwin o Magnetic materials

- Phase transformations

- Spin echo techniques

o Cryogenics

C. J. Glinka o SANS microstructure of metals and porous media

- Magnetic materials

o Cold neutron instrument development

P. H. Graham o Engineering design

G. C. Greene o System and user software for cold neutron instrumentation

o Spectrometer and data acquisition system interfaces

B. Hammouda o SANS from polymer systems 
- Quasielastic scattering from polymer solutions

- SANS instrument development

V. L. Karen o Crystal database development

o X-ray crystallography

P. A. Kopetka o Mechanical engineering

- Cold source design

o Electro-mechanical systems

S. J. Krueger o Small angle neutron scattering instrumentation

o Microstructure of materials

- Biological problems

J. G. LaRock o Mechanical engineering

o Neutron instrumentation design

H. P. Layer o Electronics and data processing

o Advanced instrumentation

o Fundamental physics

J. W. Lynn o Condensed matter physics

- Magnetic materials

- Neutron scattering methods

C. F. Majkrzak o Condensed matter physics

- Polarized neutron scattering and instrumentation development

o Neutron reflectivity measurements

A. D. Mighell o Crystallographic database development

- Single crystal diffraction

- Theory of crystal lattices

B. Mozer o Structure and microstructure of metallic glasses

- Dynamics of liquids

- NDE of alloys

D. A. Neumann o Condensed matter physics

o Two-dimensional materials

o Neutron and $\mathrm{x}$-ray scattering instrumentation

J. H. Nicklas o Mechanical engineering

- Reactor fuel design

- Reactor engineering support

D. J. Pierce

- Mechanical engineering 
o Neutron instrumentation design

H. J. Prask

o Residual stress measurement

o Neutron NDE of hardware

o Neutron NDE instrumentation

E. Prince

- Structural properties of alloys, catalysts and minerals

o Advanced crystallographic refinement methods

o Software for materials structure analyses

T. M. Raby

o Reactor operations

o Nuclear engineering

o Reactor standards

J. L. Robertson o Quasicrystals

- Structure of amorphous solids

- Structural properities of alloys

J. M. Rowe

- Orientationally disordered solids

o Hydrogen in metals

- Cold neutron research and instrumentation

J. J. Rush o Catalysts and molecular materials

o Hydrogen in metals

o Two-dimensional systems

- Inelastic scattering methods

A. Santoro o Structure of electronic and structured ceramics

- Theory of crystal lattices

- Powder diffraction methods

S. K. Satija

o Low-dimensional molecular systems

- Fractal aspects of microporous media

- Neutron reflectometry

I. G. Schröder o Cold neutron instrumentation development

- Nuclear and engineering physics

o Optical devices for neutron transport

J. K. Stalick

o Neutron and $x$-ray diffraction

o Inorganic chemistry

o Crystal database development

J. B. Sturrock o Design engineering

o Nuclear systems and components

M. Suthar

o Design engineering 
o Nuclear systems and components

J. F. Torrence o Reactor supervision

- Reactor maintenance

o Nuclear engineering

T. J. Udovic o Neutron time-of-flight instrumentation

- Properties of catalysts

- Spectroscopy of surfaces

R. E. Williams o Cold neutron source development

o Nuclear engineering

\section{Reactor Operations}

Richard D. Beasley

Nathan A. Bickford

Mark G. Cassells

Forrest C. Clark

Howard W. Dilks

Daniel J. Flynn

Larry $T$. Lindstrom

Michael J. McDonald
William W. Mueller

Thomas J. Myers

John H. Ring

Ricky P. Sprow

Robert F. Stiber

Attila L. Toth

Daniel P. Wilkison

Kevin I. Wright

\section{Neutron Research}

George M. Baltic

Douglas Bostian

David Clem

Donald H. Fravel

Thomas A. Green

Wayne C. Knill
Michael J. Rinehart

Lew Robeson

William H. Rymes

Dan E. Swearingen

Thuan T. Thai

Robert H. Williams

Reactor Engineering

James A. Beatty

Richard P. Hayes

Lynn A. Shuman 


\section{Description of Technical Activities}

The Technical Activities of the Division are summarized in this section. A more detailed description of each project can be found in the NIST Technical Note "NIST Reactor: Summary of Activities July 1990 through June 1991. 


\title{
REACTOR OPERATIONS AND ENGINEERING
}

\author{
T. M. Raby, J. H. Nicklas, and J. F. Torrence
}

Reactor operation during the past year has been uneventful and essentially routine. The reactor operated approximately $90 \%$ of all available reactor time. The small amount of lost time was mainly caused by minor heat exchanger leaks and outside electrical power interruptions. Fuel utilization continues to be the best in the United States and will improve further in the coming years. Reactor utilization is at its peak. Highlights of significant items are outlined below.

Guide Tubes. The isolation valves for the first three cold neutron guide tubes became fully operational. The isolation valve for a fourth tube was installed and successfully tested clearing the way for installation of the guide.

Main Heat Exchangers. Minor leaks continued to develop in one of the main primary heat exchangers. The size of the leak was so small, on the order of one drop a minute, that it was virtually impossible to find among the 1200 tubes of the exchanger. This has caused extra days of shutdown plus added exposure to personnel. In April 1991, the leaky heat exchanger was removed from service. Operations continued utilizing the remaining heat exchanger at reduced power. Analysis indicated that a maximum of $15 \mathrm{MW}$ of power could be achieved under almost all weather conditions. This turned out to be not only the maximum but the optimum for operation with a single heat exchanger. Operations in this mode will continue for the foreseeable future. The leaky heat exchanger is being monitored and maintained and could be returned to service if needed. Negotiations for new replacement heat exchangers of a different plate-type design have been completed. Special emphasis on quality and reliability has been incorporated in the specifications. Fabrication is scheduled to be completed in 1992.

New Advanced Fuel. The fifth generation of advanced fuel elements was introduced into the reactor in April 1991. This will further improve fuel utilization thereby extending the operating cycle. The new elements are the heaviest loaded in the history of the facility and contain more than twice the uranium loading of the original elements. This loading is the highest that can be used at the NBSR.

Control Room Upgrade. Plans are being prepared for a complete upgrade of the reactor control room once funding becomes available. Meantime, several segments and components have been modernized and upgraded.

Staffing. Two new operators received NRC senior licenses with high marks. The staff of 16 operators, the smallest for any comparable reactor, all hold senior licenses. Two senior nuclear engineers are spending a one year sabbatical at the Division and will be assisting in the reactor modernization plan. 


\title{
NEUTRON CONDENSED MATTER SCIENCE
}

\section{MICROSCOPIC PROPERTIES OF CHEMICAL MATERIALS}

N. F. Berk, R. C. Casella, J.R.D. Copley, D. A. Neumann, J. J. Rush, T. J. Udovic, S. K. Satija, P. Depondt ${ }^{1}$, W. A. Kamitakahara ${ }^{2}$, J. M. $\mathrm{Nicol}^{2}$, B. J. $\mathrm{Olivier}^{3}$, S. F. Trevino ${ }^{4}$, R. L. Capalletti ${ }^{5}$

\author{
${ }^{1}$ Guest Scientist, University of Pierre et Marie Curie (Paris) \\ ${ }^{2}$ Guest Scientist, University of Maryland \\ ${ }^{3}$ Guest Scientist, Sandia National Laboratory \\ ${ }^{4}$ Guest Scientist, U.S. Army Armament Munitions, and Chemical Command \\ ${ }^{5}$ Guest Scientist, Ohio University
}

\section{MOLECULAR SOLIDS}

The molecular solids currently generating the most excitement both in the Reactor Radiation Division and in the scientific community in general are the fullerenes. Our research has thus far focused on the prototypical example of this class of molecule, buckminsterfullerene, which contains 60 carbon atoms arranged in the shape of a soccer ball. This high degree of symmetry renders most of the vibrational modes Raman and infrared inactive, making neutron scattering an important tool in the determination of intramolecular vibration and frequencies. Our research (with Penn State) has resulted in the observation and assignment of several vibrational modes not previously observed as well as a complete intramolecular vibrational density of states up to 220 $\mathrm{meV}$. These results clearly display the three peak structure in the energy range of $40-120 \mathrm{meV}$, characteristic of 3-fold coordinated carbon. More importantly, this work has demonstrated that none of the current models of interatomic interactions within a $\mathrm{C}_{60}$ molecule is capable of adequately describing the vibrational spectrum of this molecule.

Our more research has focused on the orientational order and dynamics of this nearly spherical molecule. Work here (in collaboration with Exxon, U. Penn, and Ohio U.) and elsewhere has demonstrated the existence of a phase transition at $\sim 257 \mathrm{~K}$ between a high temperature, orientationally disordered fcc phase and a low temperature, orientational by ordered simple cubic phase. Our results for the low temperature phase can only be fit by assuming some residual disorder in the low temperature $\mathrm{Pa} 3$ structure, whose nature is currently under analysis.

We have also examined the orientational dynamics in both phases and have shown that the diffuse scattering in the high temperature phase is completely quasielastic and can be described by a model in which each molecule undergoes rotational diffusion which is uncorrelated with the motion of its neighbors. At $260 \mathrm{~K}$ and 520 the rotational diffusion constant was found to be 1.4 $\times 10^{10} \mathrm{~s}^{-1}$ and $2.8 \times 10^{10} \mathrm{~s}^{-1}$ respectively. In the low temperature phase, we have observed inelastic neutron scattering due to molecular librations of the molecules which soften from an energy of about $2.75 \mathrm{meV}$ at $20 \mathrm{~K}$ to about $2 \mathrm{meV}$ just below the transition. In addition, the mode becomes very anharmonic as the temperature is increased, reaching a width of $\sim 2 \mathrm{meV}$ 
just below the transition. A simple classical calculation suggests that the amplitude of the libration reaches about $8^{\circ}$ just before the scattering collapses from a damped inelastic peak to the quasielastic scattering characteristic of the disordered phase. We have also found that the transition is accompanied by a fractional volume change of 0.009 . Thus a comprehensive picture of the orientational dynamics in both phases has been obtained. Current work is concentrating on relating the dynamics to the phase transition and quantitatively describing the intensity of the librational mode as a function of wavevector.

Research has continued on the determination of the details of $\mathrm{H}-\mathrm{O}$ interactions in solid nitromethane, $\mathrm{CH}_{3} \mathrm{NO}_{2}$ (with Aberdeen). During the past year a modified potential was obtained which, unlike previous models, predicts both the observed spectral features due to methyl rotations and the known equilibrium methyl orientation. In addition, this potential predicts that the equilibrium orientation of the $\mathrm{CH}_{3}$, group changes as a function of pressure and a search for this effect is underway. Motivated by this success a determination of the rotational potential in aceta nitrite, $\mathrm{CH}_{3} \mathrm{CN}$, using similar techniques was undertaken. Our work to date has resulted in the demonstration that all methyl groups sit in crystallographically equivalent sites and therefore all are subject to the same potential. However, inelastic scattering results have shown that the barrier to methyl rotations is $\sim 120 \mathrm{meV}$ compared to $20 \mathrm{meV}$ for nitromethane. It is therefore impossible to observe the tunneling transition, and it thus, appears that the H-N potential in acetonitrile will not be mapped out in detail to the extent achieved for nitromethene.

\section{CATALYTIC, POROUS AND LAYERED MATERIALS}

During the past year we have continued our work on the structure and dynamics of adsorbed species inside porous frameworks and intercalation compounds.

Work has progressed (with ETH) on the structure and dynamics of water in sodalite where our recent diffraction studies have shown, contrary to previous studies, that the oxygen atom of the hydroxyl group does not occupy the center of the socalite cage. It is actually somewhat displaced so that the center of gravity of the $\mathrm{OH}$ group occupies the center of the cage. In addition a shorter $\mathrm{O}-\mathrm{H}$ distance was found, compatible with our recent quasielastic scattering measurements on $\mathrm{H}$ diffusion in these compounds. The quasielastic data also suggest a two site model for the rotational dynamics of the hydrogen, which indicates the possible presence of a trigonal deformation of the cage.

Among the most interesting effects observed for condensed matter confined in small pores is supercooling, a depression of the temperature of a phase transition below its bulk value, and hysteresis of the phase transition between cooling and warming. During the past year we have studied the structure and phase transitions of nitrogen adsorbed in porous vycor glass (in collaboration with Penn State). A sharp transition, marked by the appearance of diffraction peaks, occurs at $59 \mathrm{~K}$, well below the bulk liquid-solid transition temperature. The hcp to fcc transition is not observed for nitrogen in vycor down to temperatures of $4.5 \mathrm{~K}$. Thus the solidsolid transition is suppressed in the presence of Vycor glass. We do, however, observe a fairly rapid change in the relative intensities of the diffraction peaks below $35 \mathrm{~K}$. We are currently exploring the nature of these changes. 
Measurements have also been carried out on the collective excitations in superfluid ${ }^{4} \mathrm{He}$, both for bulk helium and helium confined in aerogel. Within the accuracy of the measurements there was no difference in the energies of the collective excitations. However, the widths of the excitations for He in aerogel are systematically larger than for the bulk. This is attributable to the fact that for helium confined in aerogel, an additional mechanism for the broadening of the excitations is scattering from the walls of the pores. The phonons, which are long wavelength excitations, are more sensitive to this effect and are therefore broadened much more than the rotons, which are thought to be highly localized excitations.

Inelastic neutron scattering measurements have also been initiated on the cubic and hexagonal forms of boron nitride (with Union Carbide and General Motors). Hexagonal boron nitride is the structural analogue of graphite, consisting of planar sheets in which each atom is threecoordinated with atoms of the other type. We find that interlayer interactions are weakened in $\mathrm{h}$-BN relative to graphite, despite the more ionic character of the former.

\section{HYDROGEN IN METALS}

This past year work has continued on systematic inelastic and quasielastic scattering studies of the details of the vibrational potentials and rapid low temperature "quantum hopping" of hydrogen in hcp rare earth metals. Observations of quasielastic scattering due to very rapid localized motion attributed to proton coupling to the conduction electrons (Kondo Effect) have been extended to different concentrations of $\mathrm{H}$ in scandium and to $\mathrm{H}$ in yttrium. The results continue to be consistent with a model in which a fraction of labile (isolated) protons in the $\mathrm{M}-\mathrm{H}_{\mathbf{x}}$ system undergo apparent local "jumps" between near neighbor $\mathrm{H}$ sites along the $\mathrm{c}$-axis at rates of $10^{11}-10^{12} \mathrm{~s}^{-1}$ at very low temperatures. Further measurements on differences in $\mathrm{H}$ vibration spectra of $\mathrm{YH}_{\mathrm{x}}, \mathrm{ScH}_{\mathrm{x}}$ and $\mathrm{LuH}_{\mathrm{x}}$ have revealed interesting correlations between the spectral lineshapes and widths, the c lattice constant and the degree of H-pair ordering.

In another area we have extended our research on hydrogen trapped by impurities in refractory metals, including a study of the random bcc alloy system, $\mathrm{Nb}_{100-\mathrm{x}} \mathrm{V}_{\mathrm{x}} \mathrm{H}_{\mathrm{y}}$, which has a hydrogen sublattice disorder with respect to site energies. Our inelastic scattering studies have established the occupation of octahedral sites at very low $H(D)$ concentrations, the only known case thus far of such behavior in bcc metals (alloys). These o-site protons also exhibit the lowest observed vibrational mode energies ever observed in a metal-hydrogen system $(38 \mathrm{meV}$ for $\mathrm{H}, 29 \mathrm{meV}$ for D). 


\title{
2. NEUTRON SCATTERING IN SUPERCONDUCTORS, MAGNETIC SYSTEMS AND
}

\section{ALLOYS}

R. W. Erwin, J. A. Borchers, C. F. Majkrzak, J. L. Robertson, J. W. Lynn ${ }^{1}$, J. K. Stalick, J.J. Rhyne ${ }^{2}$, S. Skanthakumar ${ }^{3}$, T. Clinton ${ }^{3}$, W. Sumarlin ${ }^{3}$, T.M. Giebultowicz ${ }^{4}$, P. Klosowski ${ }^{4}$, C. Broholm ${ }^{5}$

\author{
${ }^{1}$ IPA Fellow, U. of Maryland \\ ${ }^{2}$ Faculty Appointee, U. of Missouri \\ ${ }^{3}$ University of Maryland \\ ${ }^{4}$ University of Notre Dame \\ ${ }^{5}$ Johns Hopkins University
}

\section{$\mathrm{HIGH}_{\mathrm{c}} \mathrm{T}_{\mathrm{c}}$ SUPERCONDUCTORS AND MAGNETISM}

There has been intense interest in the question of the pairing mechanism in high- $T_{c}$ oxide superconductors, and in particular whether phonons play any role. The neutron scattering group and University of Maryland scientists have tested the conventional pairing mechanism by measuring the phonon density of states with inelastic neutron scattering in 2-1-4 "electron" superconductors, and comparing the results with point-contact-tunneling measurements. While the neutron results are often contaminated by the effects of crystal field excitations from the rareearths comparative studies are nevertheless possible. Reasonable agreement has been found between these two techniques for the low energy peaks at $13 \mathrm{meV}$ and $40 \mathrm{meV}$ in $(\mathrm{Nd}-\mathrm{Ce})_{2} \mathrm{CuO}_{4}$. The correspondence at higher energies is not good, but probably reflects the difficulty in obtaining quantitative tunneling data. Also, the phonon density of states has now been measured in $(\mathrm{Pr}-\mathrm{Ce})_{2} \mathrm{CuO}_{4}$ and its parent insulating compound $\mathrm{Pr}_{2} \mathrm{CuO}_{4}$ with inelastic neutron scattering. There are substantial decreases in some of the phonon peaks on changing to the superconducting sample. It will be interesting to compare this trend with the tunneling data when they become available.

A second promising mechanism for pairing in the superconducting state may arise from magnetic interactions, and there are now a number of experimental results which suggest this connection. At NIST this has been investigated with neutron scattering by searching for a suppression of magnetic fluctuations in oxide superconductors. In $\mathrm{La}_{2} \mathrm{CuO}_{4}$ weakly doped into the spin-glass regime (a collaboration with MIT) the magnetic excitations have been measured and related to the antiferromagnetic spin susceptibility. It was found that this susceptibility is a homogeneous function of the excitation energy divided by the temperature. Possibly, this result can explain the linear temperature dependence of the normal state resistivity, thus relating magnetic fluctuations with the transport properties. Similar measurements have been made in $\mathrm{YBa}_{2} \mathrm{Cu}_{3} \mathrm{O}_{6.6}$ with $\mathrm{T}_{\mathrm{c}}=53 \mathrm{~K}$ (a collaboration with BNL). These measurements find a complete suppression, or energy gap, for excitations below about $5 \mathrm{meV}$ which is approximately equal to $\mathrm{T}_{\mathrm{c}}$. This gap appears to be strongly correlated to the amount of oxygen doping, but shows little temperature dependence through $\mathrm{T}_{\mathrm{c}}$. 
A program to measure the rare-earth and $\mathrm{Cu}-\mathrm{O}$ magnetic structures in high- $\mathrm{T}_{\mathrm{c}}$ superconductors has continued during the past year with neutron diffraction in $\mathrm{DyBa}_{2} \mathrm{Cu}_{3} \mathrm{O}_{7}$ and $\mathrm{ErBa}_{2} \mathrm{Cu}_{3} \mathrm{O}_{7}$. The rare-earth magnetic moments are well localized in these materials and are thus decoupled from the $\mathrm{Cu}$ magnetism, and the magnetic phase transitions are 2-d like since the interactions along the c-axis direction are relatively weak. This has provided a unique opportunity to study low dimensional magnetism. On the other hand the rare-earth magnetism has been shown to be coupled to the $\mathrm{Cu}$ magnetism in $\mathrm{Nd}_{2-\mathrm{x}} \mathrm{Ce}_{\mathrm{x}} \mathrm{CuO}_{4}$, but not in $\mathrm{Sm}_{2} \mathrm{CuO}_{4}$.

\section{LOW DIMENSIONAL AND DISORDERED MATERIALS}

One of the latest trends in materials engineering has been to tailor properties by the epitaxial layered growth of several different constituents. This has been true in particular for magnetic materials where the magnetic structure and magnetic properties can be strongly influenced by interfacial anisotropy and coherency strains. During the past year we have continued to investigate layered rare-earth superlattices where magnetoelastic effects are pronounced, and in particular where the basal plane of a heavy magnetic rare-earth is compressed by epitaxial growth. We have confirmed that Dy grown with Lu shows a stable helimagnetic phase over only about $20 \mathrm{~K}$, compared to $100 \mathrm{~K}$ for bulk Dy. This enhancement of the ferromagnetic phase is concomitant with a suppression of the helimagnetic turn angle to 26 degrees which is the value in bulk Dy just before the ferromagnetic transition. We have also found that the coupling between ferromagnetic layers in the Dy|Lu superlattices is almost exclusively antiferromagnetic. We are currently attempting to fit these results into our magnetoelastic theory for layered materials. We have also obtained preliminary results for Dy|Sc superlattices where it may be possible to enhance the basal plane compression produced in $\mathrm{Dy} / \mathrm{Lu}$, because the intrinsic lattice mismatch is increased to 8 percent compared to 3 percent for Dy|Lu. The initial neutron diffraction results also suggest ferromagnetism at high temperatures compared to bulk Dy. Another project has measured the anisotropy of the spin coupling in $\mathrm{Gd} \mid \mathrm{Y}$ superlattices, determined from the critical fields for destroying the inter-layer antiferromagnetic coupling in $\mathrm{c}$-axis and b-axis growth materials. These critical fields are on the order of $1000 \mathrm{Oe}$ for the caxis growth and only tens of Oe for the b-axis growth. This result confirms band structure calculations of the conduction electron susceptibility in these rare-earths.

Another class of layered materials which we are continuing to study is magnetic-semiconductor films and superlattices (a collaboration with the University of Notre Dame). Neutron diffraction measurements have again concentrated on determining the effects of strain on the magnetic order and phase transitions in these materials. For example, the crossover from first to second order phase transition has been studied extensively in the $\mathrm{ZnTe} / \mathrm{MnSe}$ superlattices and $\mathrm{Zn}_{1-\mathrm{x}} \mathrm{Mn}_{\mathrm{x}} \mathrm{Te}$ epilayers for $\mathrm{x}<0.94$. Also, an incommensurate helicoidal antiferromagnetic state has been found in the superlattices with compressive strain.

A relatively new class of layered magnetic materials are the transition metal oxide superlattices. These materials are important candidates for biasing magneto-resistive recording heads. At NIST preliminary magnetic neutron diffraction results on a $\mathrm{CoO}(1.6 \mathrm{~nm})-\mathrm{NiO}(1.2 \mathrm{~nm})$ superlattice suggest that the $\mathrm{Co}$ and $\mathrm{Ni}$ layers order at the same temperature. We are currently investigating this proximity effect by studying the phase transition as a function of the layer thicknesses. 
Although the spin dynamics in disordered magnetic materials have been studied for many years, there remain several mysteries concerning the relationship of the dynamics to the bulk magnetic properties. For example, in the class of materials known as "Invar", the observed reduction of the bulk magnetization with temperature is more rapid than can be explained by conventional spin-wave theory. Using polarized beam inelastic neutron scattering, longitudinal magnetic excitations have been observed in amorphous $\mathrm{Fe}_{86} \mathrm{~B}_{14}$ at low temperatures. These new results may be a direct observation of the "hidden excitations" necessary to resolve the discrepancies with conventional spin-wave theory.

There has been a great deal of interest in low-dimensional magnetic systems where quantum fluctuations are expected to be important. A large part of this interest has centered on the prediction and experimental confirmation of the Haldane gap for the magnetic excitations in a one-dimensional system. In the past year a collaboration with Johns Hopkins University has begun to measure the complete dispersion curves in such a prototypical one dimensional system, NENP, which is an organic compound containing nickel chains. Large single crystals have been laboriously grown for this purpose. In this compound the nickel ions have a spin of unity so that the Haldane gap is observed. A complete set of measurements of the intensities and dispersion of the magnetic fluctuations will be important in refining the current theory for one-dimensional magnets.

Theoretical calculations of the spin dynamics in frustrated magnetic systems have also been carried out in the past year (a collaboration with Texas A\&M University). Exact spin-wave calculations for a frustrated spin-system, the generalized Villain model, have shown the effects of canting on the normal modes and structure factors. These calculations suggest that mode softening and additional antiferromagnetic modes should be observed near the zone-boundary region of reciprocal space in a canted spin system.

\section{NANOCOMPOSITE MAGNETIC MATERIALS}

Nanocomposites, like layered materials, attempt to combine the properties of their constituents. In collaboration with Johns Hopkins University, we have studied nanometer sized iron magnetic particles embedded in an insulating matrix of alumina. This composite is expected to have unique magnetic properties, because the particles are smaller than the critical size for domain formation, and the insulating matrix suppresses interactions between the particles. We have studied the magnetic structure and dynamics of these particles by small angle scattering techniques. Our attempts to measure the instantaneous correlation function suggest that the particles consist of a magnetic hard core and a surface layer which freezes as the temperature is lowered. The scattering law for the thermal fluctuations measured by this technique has the unusual form of a squared-Lorentzian.

\section{ALLOY PHYSICS}

We have been studying alloy phase transformations in a collaboration with the University of Houston. Specifically, we have been engaged in a systematic X-ray and neutron scattering study of a prototype body-centered cubic (bcc) to $\sigma$-phase transformation where the existence of partial 
ordering in the bcc phase prior to the phase transition has been suggested. In the simple case of a binary alloy, where the sizes of the two atomic species are nearly the same, the intensity of the diffuse scattering includes a term proportional to the Fourier transform of the pair correlation function plus scattering from the pretransitional atomic displacements which will peak near the Bragg peaks (Huang scattering). Although the $\alpha$ to $\sigma$-phase transition is first order, it is quite conceivable that one can study an $\alpha$-phase binary alloy near the $\sigma$-phase transition to observe an indication of the impending phase transition from the disordered bcc phase to a mostly ordered body-centered tetragonal structure. In particular, we are interested in the development of local icosahedral clusters in the $\alpha$-phase that serve as precursor fluctuations for the complex FrankKasper $(\sigma)$ phase. It is believed that these fluctuations are related to other intrinsic softenings in bcc structures such as the $\omega$-phase and related martensitic transformations. Thus far, no such fluctuations have been observed in the room temperature diffuse scattering on a quenched alloy $\left(\mathrm{Fe}_{53} \mathrm{Cr}_{47}\right)$ or in the phonon dispersion curves. Further investigations will center on a detailed in-situ study using elastic neutron scattering of the temperature dependence of the short-rangeorder parameters and displacement scattering, and possible anomalies in the phonon dispersion curves as the temperature is reduced to near the $\sigma$-phase transition.

\title{
3. NEUTRON DIFFRACTION METHODS AND APPLICATIONS
}

\author{
E. Prince, A. Santoro, J. K. Stalick, B. Mozer, H. J. Prask, C. S. Choi ${ }^{1}$, \\ O. Elsenhans ${ }^{2}$, Q. Huang ${ }^{3}$
}

${ }^{1}$ Guest Scientist, U.S. Army Armament Munitions and Chemical Command

${ }^{2}$ Guest Scientist, Paul Scherrer Institute, Switzerland

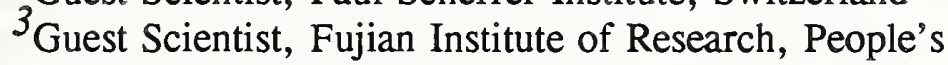

Republic of China

Crystallographic research during the past year has continued to reflect a wide diversity of applications in solid state and materials science, ranging from structure studies of superconductors, catalysts, ionic conductors and alloys to residual stress and texture studies to development of improved methods for protein crystallography, phase impurity determination and sophisticated database development.

Our extensive research on the solid state and structural chemistry of ceramic superconductors and related oxides (with Bell Labs., DuPont, SUNY and others) this past year has focussed on the effects of substitution of different metals (e.g. Co, $\mathrm{Ga}, \mathrm{Al}, \mathrm{Fe}$ ) for $\mathrm{Cu}$ in 1,2,3 type superconductors Systematic studies of changes in oxygen coordination and of relative effects of $\mathrm{Cu}(1)$ "chain" and $\mathrm{Cu}(2)$ "plane" site substitution have been carried out in $\mathrm{YSr}_{2}\left(\mathrm{CoCu}_{2}\right) \mathrm{O}_{7}$, $\mathrm{YSr}_{2}\left(\mathrm{GaCu}_{2}\right) \mathrm{O}_{7}$ and $\mathrm{YSr}_{2}\left(\mathrm{AlCu}_{2}\right) \mathrm{O}_{7}$. The previously observed destruction of superconductivity when plane $\mathrm{Cu}(2)$ sites are occupied is confirmed by these structure results. In particular, for example, it is shown that the presence of only $7 \%$ of Co on these sites is more than sufficient to preclude the occurrence of superconductivity. These and similar studies have also demonstrated that $\mathrm{Cu}$ substitution (e.g. with $\mathrm{Al}$ ) can trigger extensive oxygen disorder in the lattice and have contributed greatly to the understanding of the phase diagrams guiding the processing of pure superconductor phases. In addition this series of studies has included the 
structure analysis of the fully $\mathrm{Fe}$ substituted derivative $\mathrm{YBa}_{2} \mathrm{Fe}_{3} \mathrm{O} 8$; the $\mathrm{Fe}(1)$ "chain" ions have octahedral coordination in the basal plane (rather than square planar) and the $\mathrm{Fe}(2)$ ions have pyramidal five-fold coordination. Polarized beam diffraction shows this iron compound to have a magnetic structure in which iron moments are coupled antiferromagnetically within each $\mathrm{FeO}_{2}$ layer.

Another part of our superconductor research effort has been the development of improved refinement methods for detection and quantitative assessment of impurity phases. We have recently demonstrated the ability to detect key impurities (e.g. $\mathrm{CuO}$ ) in oxide superconductors down to less than 0.5 weight percent, to our knowledge the greatest sensitivity yet achieved for these systems.

Our structure research on the catalysts includes studies of the solid state chemistry of nonaluminosilicate molecular sieves, which have recently undergone a renaissance following the discovery of a number of phases in which the framework aluminum and silicon are replaced by phosphorous, gallium and beryllium. Some of these materials are isostructures of known aluminosilicates while others have entirely new framework topologies. Our studies (with UCSB) have elucidated structural details of several BePO and $\mathrm{ZnPO}$ analogies of zeolite $\mathrm{X}$, a synthetic version of the mineral faujasite. This work has resulted in locating three distinct $\mathrm{Na}$ sites in $\mathrm{NaBePO}-\mathrm{X}$ and $\mathrm{Na}\left[\left(\mathrm{CH}_{3}\right)_{4} \mathrm{~N}\right] \mathrm{ZnPO}-\mathrm{X}$ on the body diagonal of the cubic cell and also two $\mathrm{Mg}$ sites in $\mathrm{MgBePO}-\mathrm{X}$. In addition these studies have confirmed that the framework consists of suboctahedral sodalite cages linked by double 6-rings, in a diamond-like array.

In another area this past year we have (with SUNY, Binghamton) carried out several structure studies of defect pyrochlore and tungsten-bronze type hydrated tungsten oxide compounds $\left(\mathrm{NaW}_{2} \mathrm{O}_{6.5} \cdot \mathrm{D}_{2} \mathrm{O} ; \mathrm{Na}_{\mathrm{x}} \mathrm{WO}_{3} \cdot \mathrm{D}_{2} \mathrm{O} ; \mathrm{Na}_{\mathrm{x}} \mathrm{WO}_{3} \cdot \mathrm{YH}_{2} \mathrm{O}\right)$, which show that the arrangement of Oxygen, sodium and bound water cannot be accommodated in an organized way in the sizable hexagonal channels in these materials. This results in substitutional disorder that has been mapped out by our diffraction studies. Such structural details are of considerable interest for aiding in the understanding of the redox and ion exchange reactions that occur in these materials.

New results this year have also been obtained in our applied diffraction studies of metals and ceramics. A joint project (with Metallurgy Division) has begun in which residual stresses induced by welding are being characterized in prototype weldments. Also in the area of residual stress measurement, nondestructive characterization of stresses in an unfatigued and a fatigued test axle has been completed (for the Society of Automotive Engineers). These results are being used to test finite element models of fatigue failure. Texture characterization has focussed on the correlation of mechanical properties and texture - as produced by different fabrication processes - in forged tantalum sheet for shaped-change munitions applications.

Finally, in our research on the application of maximum entropy to the determination and extension of phases in macromolecular crystallography (in collaboration with the Chalmers University of Technology, Göteborg, Sweden) efforts have been directed toward completion of a package of computer programs for testing various strategies. Because these studies are inevitably computer intensive, careful attention has been given to utilizing modern fast Fourier transform (FFT) techniques, including consideration of space group symmetry. The programs have been used in studies directed at determining what the necessary conditions are for 
determining phases that will produce an interpretable electron density map. The application to data from bovine heart creative kinase, a protein with 381 amino acid residues whose structure is unknown, produced a map in which the diversion between molecules is clearly visible, and that contains common features of secondary protein structure such as alpha helices and beta sheets.

\section{NIST CRYSTAL AND ELECTRON DIFFRACTION DATA CENTER}

\section{L. Karen and A. D. Mighell}

The NIST Crystal and Electron Diffraction Data Center is concerned with the collection, evaluation and dissemination of data on solid-state materials. The Data Center maintains a central database with chemical, physical, and crystallographic information on all types of wellcharacterized substances. These materials fall into the following categories: inorganics, organics, organometallics, metals, intermetallics and minerals. During this year, the master database has been significantly augmented with respect to all categories of materials and now contains greater than 170,000 entries. From this central database, two distribution databases are produced: (1) NIST CRYSTAL DATA and (2) the NIST/Sandia/ICDD Electron Diffraction Database. These databases are made available to the scientific community through computer oriented modes of dissemination including: magnetic tape, on-line searching, CD-ROM, and scientific instruments. Recent developments and applications with respect to the first two of these distribution modes are briefly discussed below.

The magnetic tape version of the Crystal Data and search software were installed by VLK in the Technical Office of Acta Crystallographica in May. Using lattice-matching techniques, each "new" structure can routinely be checked against the database to see if the compound, or related structure, has been previously studied. As the lattice/element-type combination uniquely characterizes a material, this type of check by the journal Editors will prevent unwanted multiple publication of the same compound.

The online system for NIST CRYSTAL DATA, known as CRYSTDAT, consists of the database along with search and analysis software. Recently, CRYSTDAT has been upgraded to include data on 183,000 crystalline compounds. The system has been significantly expanded to include over 26 million searchable parameters. New search tools that are based on Boolean logic have been added. CRYSTDAT is ideal for analytical purposes, materials research and statistical studies. For example, statistical analyses of space group frequencies for various classes of materials have been carried out and the results will be published in 1992 . 


\title{
4. MATERIALS MICROSTRUCTURE AND INTERFACES
}

\section{SMALL ANGLE NEUTRON SCATTERING}

\author{
C. J. Glinka, B. Hammouda, S. J. Krueger, \\ J. G. Barker and M. Y. Lin ${ }^{1}$ \\ ${ }^{1}$ Guest Scientist, Exxon Research and Engineering Company
}

SANS experiments resumed in the CNRF's guide hall in October, 1990, when the relocation of the $8 \mathrm{~m}$ SANS instrument, that had previously operated at the cold source in the reactor hall, was completed at guide NG-5. The measured flux at the sample at the new location, at the end of $45 \mathrm{~m}$ of neutron guide, is greater that $85 \%$ of the flux at the former site. The ambient background, however, is much lower in the guide hall and this has resulted in an improvement in signal-to-noise of more than a factor of five that has dramatically improved the quality of measurements, particularly on weak scattering systems. Some examples of experiments performed on this instrument in which Reactor staff and guest scientists have played a principal role are briefly described below.

The recent extension of the RPA formalism for polymer blends to multicomponent systems has been used in the first determination of the individual interaction parameters among the components of a ternary blend (PSD/PSH/PVME). This result establishes a method for predicting the phase behavior of binary blends that is free from the uncertainties (due to shifts in the spinodal temperatures) introduced by isotopic labelling of one of the components. In another novel application, SANS has been used to study the macroscopic diffusion of a liquid in a microporous medium. By first imbibing a zero contrast mixture of normal and perdeuterated hexane into microporous vycor, and then exposing the sample to a reservoir of normal hexane, the self-diffusion through the pore structure could be monitored through the intensity of the SANS signal, providing a direct determination of the tortuosity of the medium. Interest in nanoscale composite materials also motivated a number of SANS studies including a detailed study of the temperature and magnetic field dependence of both the intra and interparticle magnetic correlations in samples of $3 \mathrm{~nm}$ iron particles dispersed in an alumina matrix.

The new 30 m SANS instrument (see Cold Neutron Project section) has already stimulated a number of SANS studies that would have been marginal or impossible without its expanded measurement range. Among these is the first detailed examination of the interparticle structure in concentrated colloidal solutions that rheological data show exhibit the phenomenon of discontinuous shear thinning. Carried out in collaboration with researchers at the University of Illinois and Oklahoma State University, using a couette-type shear cell developed for the CNRF by NIST's Thermophysics Division, the SANS measurements made on aqueous solutions of charged $230 \mathrm{~nm}$ latex particles reveal a nonequilibrium structural phase transformation between two distinct states with long range order that differ only in the direction of the velocity gradient. Furthermore the high shear rate structure was observed to remain stable up to shear rates of 2000 $\mathrm{sec}^{-1}$. Structural changes induced by shear have also been the focus of recent measurements on polymer blends and solutions. In one study of dilute solutions of high molecular weight $\left(2 \times 10^{6}\right.$ polystyrene), it has been observed that shear induces polymer aggregation that mimics phase separation and yet is reversible; a surprising result that contrasts markedly with the behavior of 
most blends which tend to become more miscible under shear flow. In yet another important area that has required the expanded range of the new instrument, the first study of biomolecular gels has been undertaken. Proteoglycan molecules that form large aggregate structures in vesicles of mast cells are being studied under solvent conditions which mimic in vivo environments as a means toward understanding the mechanisms underlying the formation and morphology of vesicles.

\section{NEUTRON REFLECTOMETRY}

\section{F. Majkrzak, S. K. Satija, and J. F. Ankner}

The thermal neutron reflectometer at beam tube BT-7 of the NBSR is used to determine chemical and magnetic density profiles, as a function of depth from the surface, of single and multilayered thin films of organic, magnetic, and superconducting materials. Reflectivities approaching $10^{-7}$ with signal-to-noise ratios of one have been obtained in cases where the background scattering from the sample itself is sufficiently low, as happens for films grown on single crystal substrates such as silicon. This sensitivity, in conjunction with high wavevector transfer (Q) resolution (as good as $0.0005 \AA^{-1}$ at the lower values of Q) makes it possible to deduce density profiles with a spatial resolution of a few Angstroms. Additional information, regarding magnetic moment direction and phase, for example, can be obtained using a polarized incident beam and/or with polarization analysis of the scattered beam. The multilayer polarizers and spin flipping devices used at BT-7 have efficiencies of $95 \%$ or better. This reflectometer is currently the best instrument of its kind in existence. Several reflectivity problems currently being studied are briefly described below.

Up in smoke-Some recent Surface Magneto Optic Kerr Effect (SMOKE) measurements performed on a Co-Cu multilayer have been interpreted to imply that the in-plane ferromagnetic Co layers ( $\sim 41 \AA$ thick separated by $10 \AA$ thick Cu layers) are antiferromagnetically aligned with respect to one another in low fields (up to about 40 Gauss). SMOKE in effect senses any magnetization which causes a measurable rotation of the plane of polarization of light reflected from a surface. This probe penetrates several hundred Angstroms and therefore has an enhanced near-surface sensitivity. However, this technique still corresponds to a bulk magnetization measurement in that the magnetization sensed is that averaged over the entire volume probed, which in the case of the Co-Cu multilayers includes most, if not all, of the 7 bilayers comprising the sample. As it turns out, in this case there is just no substitute for the detailed microscopic information regarding the magnitude and orientation of atomic moments which can be obtained by polarized neutron reflectometry. Together with university scientists, polarized neutron reflectivity measurements were performed on the $\mathrm{Co}-\mathrm{Cu}$ multilayer which demonstrated unambiguously the absence of the telltale doubled periodicity which must arise from antiferromagnetically aligned Co layers. The neutron data further showed the presence of in-plane anisotropy which prevents complete alignment of ferromagnetic Co domains at low applied fields and offers an alternative explanation of the observed SMOKE signals.

Current problems and potential solutions-i.e., electrochemistry performed in situ as neutron reflectivity measurements are made. Because of the high transmission of neutrons through single crystals of Si or sapphire, such crystals can serve not only as the substrate for various films in 
contact with solution, but as the incident medium as well. This makes possible studies of the chemical composition profile normal to the surface of thin films acting as an electrode in intimate contact with the solution in an active electrochemical cell. One problem involves the determination of whether the passive oxide layer formed on an Fe film in contact with an aqueous solution at a given applied electric potential is $\mathrm{FeO}-\mathrm{OH}$ or $\mathrm{Fe}_{3} \mathrm{O}_{4}$. With polarized neutrons, distinguishing even very thin films (as low as 10-20 $\AA$ ) of these two species is in principle possible because of the magnetic nature of the $\mathrm{Fe}_{3} \mathrm{O}_{4}$. However, other interesting phenomena, believed to involve hydrogen diffusion in the reducing state, have been observed and are complicating the analysis. Work on these fundamental problems in electrochemistry is being pursued in collaboration with G. Long, (NIST), and Johns Hopkins University researchers. Of related interest are biological membranes consisting of lipid and protein molecules which form continuous bilayers whose response to an applied electrical potential while in contact with an aqueous solution can also be studied by neutron reflectometry. For instance, some membrane proteins form channels which allow certain molecules of appropriate size and charge to pass through when the protein changes conformation in response to an electrical potential which causes the channel to open. We are working on such a system, a mitochondrial outer membrane, with S. Krueger, (NIST), and University of Maryland scientists, to probe the action of the channel proteins by measuring differences in the neutron reflectivity data for bilayer density profiles corresponding to the open and closed states.

Survival of the fittest-also applies to the world of neutron reflectivity data analysis. Because of the relatively high reflectivities (approaching unity at low wavevector transfers), a dynamical theory of reflection which accounts for the appreciable distortion of the incident wave is required to correctly extract density profiles from the reflectivity data. In practice, a direct comparison between measured reflectivity data and that calculated for a particular model of the real space density profile is often performed with varying degrees of agreement by trial and error. J. Ankner has improved upon this process by developing a sophisticated non-linear least squares program which can be used to automatically vary parameters to obtain the best model fit to the observed reflectivities. In some cases, however, the loss of phase information (the measured reflectivities or intensities are proportional to the square of the structure factor) is sufficient that a unique real space density profile cannot be accurately obtained from a given reflectivity profile. We are currently working on phase shifting techniques, analogous to the method of isomorphic substitution employed in conventional crystallography, making use of buried ferromagnetic layers as the phase shifters for polarized neutrons. Difference data can then be obtained which can be used to deduce the real space density profile by Fourier transformation. This technique is being developed with BNL and Exxon physicists who have been interested in a similar method for $\mathrm{x}$-ray reflectivity.

Brushes paint a picture-of the segment density profile for polymers adsorbed on a surface. It has been predicted that a parabolic density profile should occur for a polymer "brush" or polymer chain terminally attached to a surface. Neutron reflectivity studies have been performed, in collaboration with groups at the University of Massachusetts and the University of Pennsylvania, on end-carboxylated polystyrene adsorbed on silicon in cyclohexane solvent, again using the silicon substrate as the incident medium for the neutrons. The results of the study confirm the existence of the predicted parabolic density profile. Other reflectivity studies of organic materials, in which selective deuteration is used to great advantage, include work with IBM, (San Jose), on the morphology of copolymer/homopolymer mixtures, for example, and with the 
University of Minnesota on the thermodynamics of diblock copolymer films. Another important class of problems, which should at least be mentioned, involves neutron reflectivity studies of interdiffusion in Langmuir-Blodgett multilayers with the University of Akron and the Max Planck Institute.

Depth of field-is what is measured when neutron reflectometry is performed on a superconducting film immersed in a magnetic field. The neutrons in effect sense the absence of the applied magnetic field when it is expelled from the superconductor. This magnetic field expulsion is not abrupt but can be described by a field which decays exponentially in from the surface, with a penetration depth characteristic of the particular superconducting material and temperature below $T_{c}$. G. Felcher of ANL pioneered neutron reflectivity studies of this magnetic field profile which occurs near the surface of a superconductor and first measured the penetration depth in $\mathrm{Nb}(\sim 400 \AA)$. Our current instrumental resolution allows us to measure penetration depths of the order of $2000 \AA$, comparable with values expected for some of the new high $\mathrm{T}_{\mathrm{c}}$ superconductors.

\section{NEUTRON ACTIVATION AUTORADIOGRAPHY OF PAINTINGS}

\section{Y. T. Cheng and J. S. Olin (Smithsonian Institution and Reactor Radiation Division, NIST) and \\ W. Leuther and C. O. Fischer (Hahn-Meitner Institute, Berlin)}

Neutron activation autoradiography applies neutron activation analysis and film autoradiography to the study of oil paintings. Sensitive $\mathrm{x}$-ray films are used to record the images processed by the decay of radioactive components in the painting following activation. The darkening of the film is mainly the result of beta-particle emission. Gamma ray spectroscopy helps in the interpretation of the autoradiographs by providing elemental analysis.

Multiple autoradiographic exposures are generated for each painting to isolate the images created by groups of isotopes with different half-lives. Films serve as convenient, high resolution area detectors for the registration of the painting's radioactivity. However, only twelve timed exposures can be made in a typical painting study due to the low efficiency of the film system. Ten of the exposures are created during the first two weeks of film exposure with the period of exposure being about equal to the time after activation of the painting.

Research was conducted to improve the radioactivity detection of the autoradiography process. A more efficient system could provide better quality autoradiographs and thereby enhance the opportunity for interpretation. Also, a more efficient system could reduce the radiation exposure needed for the activation of the painting. We are presently activating painting for 20 to $30 \mathrm{~min}$ at $3 \times 10^{2}$ neutrons $/ \mathrm{cm}^{2} / \mathrm{sec}$. This exposes the painting to between 300 and 500 rads of gamma radiation as determined by measurements made using TLD detectors at the thermal column where the paintings are activated.

An experiment was carried out to test the usage of light scintillation screens for film speed enhancement. Kodak XAR Films, recommended by the manufacturer for autoradiography use, were used throughout the experiment. The film-screen combination is commonly used in medical 
$\mathrm{x}$-ray applications. However, the effect on beta-particle detection is not well known. For the experiment ten different scintillation screens were used. The screens were selected for their light emission spectrum, resolution and physical properties (thickness, light transparency). Gold foils were activated to simulate a pigment in a painting.

The results show that the efficiency of the current no-screen film system can be improved by selecting a proper film screen combination. It is characteristic that within the normal useful range of $x$-ray film the density reading is linearly proportional to the logarithm of exposure time. Based on the data, the use of Rego NPR screen with film can be seen to reduce the necessary exposure time ten fold or more over the current no-screen film practice. A more precise speed enhancement factor will be determined by generating the specific film response characteristics with respect to beta particle exposures. It will also be important to investigate the effect of different beta particle energies on the speed enhancement factor. Efforts are now being made to obtain a large size screen on flexible backing fabricated for autoradiography use.

Another objective was to study the feasibility of converting radioactivity into visible light through scintillation screens in order to capture the light output by electronic video means. This was to prepare for the eventual change to a filmless autoradiography system.

Typically, a gold beta particle fluence of $1 \times 10^{6} / \mathrm{cm}^{2}$ is required to darken film to a $1 \mathrm{D}$ reading. A density of $1 \mathrm{D}$ allows detection of differences of $3 \%$. To allow equivalent differences to be distinguished in a filmless system requires $1 \times 10^{3}$ photons $/ \mathrm{cm}^{2}$ (3\% counting statistics). Therefore an electronic light photon detection system can in principle improve the present efficiency by as much as three orders of magnitude and at the same time usher the autoradiography technique into a new age by incorporating computer image processing advancement.

For our experiment the light output from scintillators was recorded by placing a film on the back side of the scintillation screen to simulate detection through the screen to an electronic detector. The results indicate the same Rego NPR screen also generates the most light. Future tests regarding photon detection will use NPR screens of various thicknesses with more transparent backing. 


\title{
COLD NEUTRON PROJECT
}

\author{
J. F. Ankner, G. Baltic, J. G. Barker, W. E. Dickerson, D. H. Fravel, \\ J. A. Gotaas, C. J. Glinka, P. H. Graham, G. C. Greene, B. Hammouda, \\ P. A. Kopetka, S. J. Krueger, J. G. LaRock, H. P. Layer, C. L. O'Connor, \\ D. J. Pierce, L. M. Pool, M. J. Rinehart, L. Robeson, J. M. Rowe, I. G. Schroder, \\ T. T. Thuai, R. E. Williams, and R. H. Williams
}

Progress in the CNRF continues, with neutron guides NG 5, 6, and 7 installed into the guide hall, and NG-3 partially installed. The prompt gamma facility, cold neutron depth profiling facility, a focussed beam research station, the 8-m SANS, the NIST/Exxon/U Minn. 30-m SANS, and the fundamental physics station are operational. The medium resolution time-of-flight spectrometer, the NSF-funded 30-m SANS, a triple-axis spectrometer, the neutron interferometry station, and the cold neutron reflectometer are at various stages of fabrication and installation. The high resolution time-of-flight spectrometer is well into the design and procurement stage, while the back scattering and spin echo spectrometers are entering the detailed design phase. The installed and operating instruments are performing essentially as predicted, with further enhancements being added as required.

The 30-m SANS (which was formally dedicated in May of this year) has provided capabilities heretofore unavailable in the U. S. The very degree of flexibility built in (variable incident and scattered flight paths of up to $15 \mathrm{~m}$ each, variable incident wavelength and wavelength resolution) has already been exploited to study anomalous shear measurements and biological problems that were simply out of reach previously. Within a few days of operation, the prompt gamma facility was used to non-destructively determine the residual hydrogen in a sample of $\mathrm{C}_{60}$, and later to characterize the degree of deuteration of a polymer sample in very short runs. Neither of these experiments was foreseen at the time of construction, and this illustrates very well the predicted synergism of an active research program in a broad variety of areas.

Methods development also continued, with primary emphasis on development of supermirrors, focussing mirrors for the 30-m SANS, and on beam focussing techniques. The problem of supermirror fabrication has been solved at the laboratory scale, and two industrial firms are now in a position to mass-produce coatings suitable for neutron guide construction. A Request for Proposals will be issued soon for such components for the top and bottom surfaces of NG-1, 2, and 4. A technique for focussing beams by using capillaries is being actively pursued in collaboration with researchers from SUNY, and has already met with some laboratory- scale success. Glass blanks for fabrication of focussing mirrors on the 30-m SANS have been received and tested. Further work is needed to reduce unwanted non-specular reflection from the coated segments in order to achieve the design goals.

As a result of extensive Monte Carlo modelling using the new Cray computer, a new design for the liquid hydrogen cold source has been developed which promises better performance, easier fabrication and more reliable operation. Detailed design is underway, and thermal hydraulics analysis and testing will be done in the next six months at the NIST Boulder laboratory. The 3.5 $\mathrm{kW}$ helium refrigerator is installed in the reactor, and is undergoing initial testing and setup, preparatory to a 40 day acceptance test. The start up has had a number of problems, but is now 
proceeding, and initial tests indicate that the performance specifications can be met with some difficulty and modification.

Two separate workshops were held during the year - one, a hands-on workshop for industrial users, in which neutron novices were introduced to SANS and reflectometry as it applied to their problems, and the other a planning workshop on the uses of high resolution neutron spectroscopy in problems of materials science, chemistry, biology and physics. Both were successful, leading to strong new interactions, and helping to specify necessary instrumentation for the scientific future. In addition the first CNRF Researchers' Group meeting was held to acquaint interested scientists with details of available instruments and the proposal review system.

The formal user program was initiated for the CNRF, with the first call for proposals going out to over 2000 researchers for time on the SANS, depth profiling and prompt gamma facilities. The response was highly gratifying, although the use of analytical chemistry instruments in this mode is not customary, and further educational efforts and outreach will be needed to more effectively use these instruments. All of the proposals were sent out for peer review; the Program Advisory Committee will meet in November to allocate time for successful proposals.

This project is now entering the final construction phase, and in coming years will have to be more oriented to operating the facility as a national resource. After FY1992, all of the facility construction funds will be in hand, and by the end of FY1993, all instruments should be in the final commissioning stage. As this transition takes place, the character of the group will necessarily change, and planning is now well underway for long term operations. 


\section{INDEPENDENT PROGRAMS}

\section{NUCLEAR METHODS GROUP}

\section{R. R. Greenberg (Inorganic Analytical Research Division)}

The development and application of nuclear analytical techniques for elemental compositional analysis of greater accuracy, higher sensitivity and better selectivity are the goals of the Nuclear Methods Group. A high level of competence has been developed in both instrumental and radiochemical neutron activation analysis (INAA and RNAA). In addition, the group has the capability of using neutron beams as analytical probes with both prompt gamma activation analysis (PGAA) and neutron depth profiling (NDP). NDP determines concentrations of several important elements (isotopes) vs. depth profiles within the first few micrometers of a surface by energy analysis of the prompt charged-particles emitted during neutron bombardment. PGAA, on the other hand, measures the total amount of an analyte present throughout a sample by the analysis of the prompt gamma-rays emitted during neutron capture. These techniques (INAA, RNAA, PGAA, and NDP) provide a powerful combination of complementary tools to address a wide variety of analytical problems of great importance in science and technology.

The use of a variety of nuclear methods has continued to contribute to the Standard Reference Material (SRM) certification effort; this year's efforts include measurements performed on a number of SRMs including: Fly Ash, Coke, Sewage Sludge, two (used) Automobile Catalysts, Apple Leaves, Peach Leaves, Tomato Leaves, Bone Ash, Bone Meal, Water, Grass, Boron in Silicon, two Wear Metals in Oils, and three Soils. Group members are serving as Technical Champions for several of these new SRMs, and are also collaborating with researchers from the Microanalysis Group (837) in developing a boron depth-profiling SRM.

Optimizing the counting conditions in the various forms of NAA can generally improve precision and/or increase sample throughput. This is especially important when counting low-activity materials. Much can be gained in sensitivity by using high-efficiency detectors. As part of our continuing efforts to improve the NAA method we have performed experiments to apply Cooper's figure of merit for detector performance to two excellent modern detectors. The results obtained show that for the ultimate sensitivity in quantitating a simple spectrum, high efficiency overwhelms good resolution, low background, or any other criterion of detector quality for a given measurement. In practice, however, the choice is not so simple, i.e., when summing corrections are large, when unresolved multiplets are present, when the total count rate is high, when background lines (not continuum) are important, when sample-detectors positioning uncertainty limits the accuracy, or when requirements of sample shape dictate the counting configuration. Long-term studies of such problems are under way.

The Biomonitoring Specimen Bank Research Project continued to support other agencies' monitoring programs. These programs include the EPA Human Liver Project, the NOAA National Status and Trends (NS\&T) program, the NCI Micronutrient program, the IAEA/NIST/FDA/USDA Total Diet Study, the NOAA Alaska Marine Mammal Project, and the National Marine Mammal Tissue Bank. Research has centered on specimen banking protocols and improved analytical methodology. The group's participation in intercalibration exercises with the project participants and the development of QA materials for various marine analyses 
has helped to enhance the quality of the analytical results used in the assessment of the environmental health of the nation. This year, the group has provided trace element measurements (for information values) in SRM 1974 (Organics in Mussel Tissue). This material is the first NIST frozen tissue homogenate available with concentrations given for both trace elements and trace organics. In addition, as part of the marine mammal projects, we have prepared a whale liver quality control material for use by other laboratories involved in marine mammal tissue measurements. The analytical experience gained from these measurements will be used to develop new SRMs for marine mammal tissues in the future.

The joint NIST/FDA/USDA study of trace elements in human diet, sponsored by the International Atomic Energy Agency, has completed its sixth year. A total of 275 diets from different countries have been analyzed to date for minor and trace elements. Preliminary data evaluation shows some interesting differences, among the countries studied, in the daily dietary intakes for several elements such as $\mathrm{As}, \mathrm{Hg}$ and $\mathrm{Se}$. Ten diets from different regions of the United States have also been collected, and thus far, seven have been analyzed. The data obtained from the U. S. diet composites have confirmed daily intake results for some of the elements investigated by the FDA (based on individual food analysis), as well as established reliable daily dietary intakes for additional elements including $\mathrm{B}, \mathrm{Cr}, \mathrm{Cs}, \mathrm{Li}$ and $\mathrm{Sn}$. In the case of $\mathrm{Li}$, the observed intake values are considerably lower than earlier published results. In addition, multiple diets from Spain, Italy and Turkey have been analyzed for B and Li. The results show considerable variation in the daily dietary intakes among the three countries.

The collaboration with Brian Clarke of McMaster University on neutron activation-mass spectrometry has continued to provide valuable information on ultratrace levels of boron and lithium. A wide variety of materials was investigated this past year, and results were obtained for boron and lithium concentrations in several different protein components in blood, various individual foods, and a number of geological reference materials. These analyses have resulted in numerous publications as well as a certified value for Boron in the Total Diet SRM.

The group has taken an active role in the NIST program on high-temperature superconductivity research, both in the measurement of impurities in starting materials and final products, and in determination of the stoichiometry of metallic constituents. The effort this year has centered on the development of accurate, rapid measurements of these materials by both NAA and PGAA. An effort to establish an accurate, monitor activation analysis technique for further study of high temperature superconductors at NIST is under way.

About a decade ago a systematic error for PGAA was observed in which element sensitivities (cps/mg) increased with increasing $\mathrm{H}$ concentration. The process responsible for the observed enhancements is neutron scattering by hydrogen within the sample. Experimental studies have shown that PGAA element sensitivities are dependent upon the scattering density (or hydrogen concentration), as well as the sample shape. Consistent with these results, Monte Carlo calculations have demonstrated that, depending on the absorption and scattering power of the sample, and on the sample size, shape and orientation with respect to the neutron beam, scattering within the sample may either increase or decrease the neutron path length in the material and thus may change the probability of neutron absorption. Therefore, an analytical signal, which follows an absorption reaction, is also a function of these variables. Theoretical work and Monte Carlo calculation experiments have demonstrated that for spherical samples, 
neutron scattering serves to mitigate the effects of neutron self-shielding, and produces no additional enhancement. PGAA measurements on spheres have confirmed this theory and have comprised the majority of the measurements performed in the past year. For most materials (e.g., paraffin, urea, SRM 1632a, SRM 1577) results show that element sensitivities for diskshaped samples (of constant $\mathrm{H}$ concentration and diameter $[12.7 \mathrm{~mm}]$ ) vary with thickness over the range of $2-12 \mathrm{~mm}$, but that sensitivities remain constant for spheres of the same materials (diameters $2-12 \mathrm{~mm}$ ). The sensitivity values for the spheres compare well with those obtained from measurements on nonhydrogenous standards, indicating that sensitivity enhancements are eliminated by using spheres. However, for some materials (aqueous solutions of $\mathrm{Gd}$ and $\mathrm{Sm}$ ), sensitivities were not constant over the same range of sphere diameters. To insure accurate data interpretation for such samples that both strongly absorb and strongly scatter neutrons, standards should be matched as closely as possible to the samples with respect to both the amount of scatterer and the amount of absorber.

During the past year, a large part of the group's efforts has been directed at the exploitation of the analytical applications of cold neutrons at the CNRF. The group's involvement has been to design and construct state-of-the-art instruments for both PGAA and NDP using cold neutrons, and has been aided substantially by the ability to use an existing cold neutron beam at the KFA Jülich facility. A new chamber for the cold neutron depth profiling (CNDP) instrument has been installed at the NIST Cold Tube West (CTW) location in the confinement building. The $60-\mathrm{cm}$ diam chamber has ultra-high vacuum capability, and has been designed to be adaptable to many different types of experiments. The final configuration allows remote scanning of $15 \times 15 \mathrm{~cm}$ samples and rotation of both sample and detector angles relative to the beam. Sample movements are controlled by a desk-top computer. Using the new instrument, the first ${ }^{17} \mathrm{O}$ depth profiles have been made in collaboration with the Eastman Kodak Company. These measurements were made on a cobalt nickel oxide produced using enriched ${ }^{17} \mathrm{O}_{2}$ gas.

A permanent, full-time instrument for prompt-gamma activation analysis (PGAA) has been constructed at the CNRF, which will allow accurate measurements of low levels of many elements including hydrogen. Hydrogen backgrounds of a few tens of micrograms have already been achieved. This promises to be of value in numerous applications where quantitative, nondestructive analysis of small quantities of hydrogen in materials is necessary. Further background reduction by one to two orders of magnitude is probable in the near future. Sensitivities (counting rates per gram of analyte) of a number of elements have been compared using the new cold-neutron instrument to those obtained with the thermal neutron U. of Maryland-NIST PGAA instrument. At the same reactor power, sensitivities for most elements are a factor of four to six better with the cold-neutron apparatus as a result of a compact sample-detector geometry. The first quantitative measurement with cold neutron PGAA in the $\mathrm{CNRF}$ was the determination of hydrogen in a sample of $\mathrm{C}_{60}$ fullerene "buckyballs" intended for neutron scattering studies. The sample was found to contain $0.077 \pm 0.014 \mathrm{wt} \% \mathrm{H}$, which was adequately low for the neutron scattering measurements. In addition, hydrogen was sought in a 50-nm borophosphosilicate glass film on one fourth of a 10-cm silicon wafer; an upper limit of $2 \mu \mathrm{g} / \mathrm{cm}^{2}$ was found.

A long-range program to explore and develop the analytical applications of focused beams of cold neutrons has been initiated within the group. The ultimate goal of this research is to produce beams of neutrons which have intensities several orders of magnitude greater than previously 
available. Such beams will greatly enhance the capabilities of both PGAA and NDP, and may ultimately lead to a neutron probe for microanalysis. The neutron micro-guide appears to be one promising approach to achieve analytically useful focused neutrons. As a first approach, a device will be developed and tested using a stack of ultrathin, nickel-coated single-crystal silicon wafers as focusing elements. The silicon wafers act as the transmission medium for the neutrons, which reflect from the $1000 \AA$ nickel surface coatings. The superposition of the individual outputs becomes the focal point. One hundred of these wafers have been obtained for tests of this first focusing element. The wafers have been characterized with X-ray reflectivity measurements at a synchrotron source. Cold-neutron measurements using a polychromatic beam at CTW have shown that these wafers can deflect the neutron trajectories successfully. More precise measurements have been performed using monochromatic neutron beams at BT-7 (NIST) and at ILL, Grenoble. These measurements, some of which include up to eleven reflections, have shown a high degree of reflectivity for the silicon-nickel interface.

Another focusing concept involves the use of capillary optics, a concept which has proven successful with X-rays, and which allows for the possibility of two dimensional focusing. In collaboration with scientists from the USSR and SUNY-Albany, we have begun testing this concept with cold neutrons. We have obtained a number of capillary fibers, each containing over a thousand individual channels within a glass diameter of less than one millimeter, and have observed the transmission (and deflection) of cold neutrons through an array of such capillaries bent to radii of curvature as small as 0.4 meters.

The strong interaction with industrial scientists using NDP, PGAA, and NAA has continued during the year with a growing number of guest workers, research associates, and joint publications. For example, working this year with researchers from Texas Instruments, we have used NDP to study various aspects of quality control using CVD (chemical vapor deposition) reactors. These measurements will be useful in optimizing process yield and reliability.

The Nuclear Methods Group is also collaborating with scientists from the NIST Physics Laboratory in a new measurement of the neutron lifetime. The technique used involves detecting the protons which decay in a neutron beam passing through a superconducting-magnet proton trap. Current efforts are concentrating on lowering the uncertainties due to neutron fluence rate measurements, one of the largest components of the uncertainty in the measurements we reported last year. A gamma-alpha coincidence technique is being used to eliminate the dependence on detector efficiency. A counting system with two germanium detectors and one alpha detector has been installed at neutron guide NG-6. Preliminary measurements are currently in progress.

During the coming year the group will continue to improve the accuracy, sensitivity and productivity of nuclear methods as applied to elemental composition measurements. Problems to be addressed include those inherent in sample preparation, irradiation, radiochemical separation, counting and data reduction, with the goal of minimizing and quantifying various sources of random and systematic errors in analysis by nuclear methods. Maintaining full accuracy at high count rates using current generation data acquisition electronics is the goal of our count-rate-dependent studies. Accurate quantification of gamma-ray self-absorption and measurement of the shape of the efficiency curve are required for accuracy in monitor activation analysis (since matching of sample with primary standards is not required). In addition to allowing rapid sample turnaround with minimum sacrifice of accuracy, monitor activation 
analysis also provides good quality control when used in parallel with traditional primary standards.

\section{NEUTRON INTERACTIONS AND DOSIMETRY}

\section{J. A. Grundl (Ionizing Radiation Division)}

The Neutron Interactions and Dosimetry Group develops and applies well-characterized neutron fields and related capabilities for neutron dosimetry methods evaluation and standardization, for detector development and calibration, and for nuclear cross section measurements. Related efforts in cold neutron physics and metrology provide a basic research component. Involvement with outside organizations, both in the federal and private sectors, includes many types of research and technology assistance projects as well as leadership roles on national and international standards and radiation policy-making bodies.

\section{DOSIMETRY FOR MATERIAL PERFORMANCE ASSESSMENT}

Dosimetry methods for monitoring the degradation of materials in high fluence neutron exposures are diverse. This project provides some form of measurement assurance, standardization, or methods development for nearly every approach to materials dosimetry employed in the United States. Inter-laboratory measurement cooperation with substantial international participation is an important feature of this project.

LiF Gamma Dosimeters for Davis-Besse Reactor Cavity Dosimetry. Nine LiF gamma dosimeters were irradiated in the Davis-Besse Nuclear Power Reactor or at the Three-Mile Island I Reactor and returned to NIST for read out. The samples have been carefully checked, and will be annealed and recalibrated by ${ }^{60} \mathrm{Co}$ exposure before results are reported.

NIST/Nuclear Regulatory Commission Contract Work. This contract provides calibrations for reactor pressure surveillance dosimetry that is traceable to NIST standard neutron fissionspectrum fields through fluence standards, which are radioactive artifacts produced by certified fluence irradiations in the standard fields. NIST also provides consultation and dosimetry assistance for NRC metallurgical test irradiation programs.

Distribution of Neutron Fluence Standards to Provide Benchmark Field Referencing of Neutron Dosimetry for Reactor Pressure Vessels and NRC Metallurgy Test Irradiations. Radiometric dosimeters (e.g. activation foils) are benchmarked for customers by certified fluence irradiation in standard neutron fields, such as the ${ }^{252} \mathrm{Cf}$ spontaneous fission field or the ${ }^{235} \mathrm{U}$ fission field at the NIST reactor. The customer measures the specific activity and uses spectrum-averaged cross sections to evaluate his prediction of the NIST certified fluence. Seventeen such fluence standards have been produced this fiscal year.

Davis-Besse Ex-Vessel Cavity Dosimetry Benchmark Experiment. The power-reactor industry's benchmark irradiation at the Davis Besse Reactor is complete and the dosimeters are being analyzed. Fluence standards have been shipped to Babcock and Willcox for the ${ }^{58} \mathrm{Ni}(\mathrm{n}, \mathrm{p})^{58} \mathrm{Co}$, ${ }^{46} \mathrm{Ti}(\mathrm{n}, \mathrm{p}){ }^{46} \mathrm{Sc}$, and ${ }^{63} \mathrm{Cu}(\mathrm{n}, \alpha){ }^{63} \mathrm{Co}$ reactions. Fluence standards are also being counted by $\mathrm{B} \& \mathrm{~W}$, 
Lynchburg Research Center, CEN/SCK, Mol, Belgium, and Arkansas Tech University, Russelville, Arkansas.

NIST has supplied, and will analyze, Paired Uranium Detectors (PUDs) for comparison with other types of fissionable dosimeters. The PUDs in Davis Besse were irradiated together with radiometrics, SSTRs, HAFMs, niobium, and LiF Chips.

Dosimetry Methods Development for Reactor Support Structures. A contract for the dosimetry has been let with the Westinghouse Science and Technology Center to monitor possible radiation damage to structural members at the Trojan Nuclear Power Reactor. The Westinghouse dosimeter-evaluation systems must be benchmarked prior to obtaining the Trojan measured results. Fluence standards were prepared in certified fluence irradiation and shipped in October. The benchmarked dosimetry will be used to make necessary adjustments to the calculations at the dosimeter locations and before extrapolation of radiation (damage) exposure to the support structures. It is now necessary to oversee implementation of the second phase of the contract with Westinghouse to derive the fast neutron fluence on TROJAN Reactor support structures. NIST will consult with ORNL to obtain comparisons of their calculated results with the measured dosimetry for TROJAN.

NRC Regulatory Guide Preparation. NIST's involvement continues in the development of a draft regulatory guide "Status of a New Regulatory Guide on Methods and Assumptions for Determining Pressure Vessel Fluence." The guide requires validation of calculational methods against benchmarked dosimetry results. NIST is preparing a NUREG for this purpose as part of a calculational benchmark package.

The Behavior of Np-237 in Ex-Vessel Cavity Fields. The Np-237 response appears to have some correlation to the behavior of non-threshold detectors. This probably is the reason so many experimenters blame unidentified quantities of Pu-239 for low C/E ratios. Both calculated response and measured cross-sections for Np-237 are being examined in this project.

Dosimetry Support for New NRC/HSST Irradiations at University of Michigan. NIST has assumed a dosimetry consultants role for the combined MEA and ORNL operations for the Heavy Section Steel Technology (HSST) Program at the University of Michigan Reactor. Specifically, tailored spectrum experiments will be undertaken, in which the epithermal fluence is enhanced by several orders of magnitude over the fluence greater than $1 \mathrm{MeV}$.

\section{RADIATION PROTECTION DOSIMETRY}

Standard neutron fields are used to calibrate radiation protection instrumentation and to investigate and test new types of dose measuring techniques. Responsibilities in national and international dosimetry methods research focuses on tissue dose modeling, and tissue equivalent proportional counter (TEPC) measurements, and the development of written standards.

Calibration Services. Approximately 35 neutron instruments were calibrated this year. Although the majority were conventional radiation protection instruments, calibrations were also done for neutron flux monitors used at radiation therapy installations, and fission chambers for use at reactor sites. 
ICRU Publication on Practical Determination of Dose Equivalent. Our ICRU report, entitled "Measurements of Dose Equivalent from External Photon and Electron Radiations", was approved by the main commission last winter, revised, and is in final form.

ISO Document on Instrument Calibration. The final draft of the standard "Procedures for Calibrating and Determining the Response of Neutron Measuring Devices Used for Radiation Protection" is being sent off to the member countries for comment before final publication as an ISO standard. A revised version of the standard, taking into account some new work, is in preparation.

Measurement of Neutron and Gamma-Ray Kerma Rates at AFRRI. Two sets of on-site measurements were performed at AFRRI to resolve a discrepancy between ratios of neutron and gamma-ray kerma rates determined with tissue-equivalent ionization chambers (TEIC) and tissue equivalent proportional counters (TEPC). The ratio obtained in one particular field with TEIC only led to anomalous results for the relative susceptibility of mice to neutron and gamma radiation. Neutron reaction rates obtained with NIST fission chambers corroborated both concurrent and earlier measurements of neutron kerma rates with TEPC. It was concluded that TEIC do not respond properly in fields with a high neutron to gamma ratio. Using the consistent ratio from TEPC and fission chambers, the neutron quality factor for mice no longer appeared anomalous.

\section{RESEARCH AND TECHNOLOGY ASSISTANCE}

Research and technology assistance are strongly coupled in neutron dosimetry. A multiplicity of institutional involvements, drawn to the group by the availability of unique irradiation facilities and measurement capabilities, encourages a variety of attractive projects and unavoidable responsibilities.

Benchmark Measurements for Criticality Safety. The transport of ${ }^{252} \mathrm{Cf}$ neutrons through spherical water moderators has been studied by observing fission rates of four isotopes in the leakage spectrum outside the moderator. Both measurements and Monte Carlo calculations with highly detailed modelling of the experiments have been compared and reported for two different water radii. The calculations tended to over-predict the thermal flux, especially for the thicker moderator.

Neutron Fluence Rate Measurements at the CNRF. The fluence rate was measured at four wavelengths for the beam coming from the velocity selector and going to the $30 \mathrm{~m}$ SANS instrument on the NG7 beam. The ${ }^{239} \mathrm{Pu}$ fission rate was found to drop by about a factor of 2 for each increase of wavelength of 2 Angstroms.

At the NG6 end-station, fluence rates for both fast neutrons and cold neutrons were measured for several different filter configurations.

Calculations of Slab Penetration. Results of a basic study of slab transmission and reflection by neutrons and gamma rays were published in Nuclear Science and Engineering. 
Upgrading Neutron Transport Calculational Capability and Converting All Radiation Transport and Related Codes to the Cray Computer. The 2-d discrete ordinates code, DORT, has been acquired and some sample problems have been run on the Cray. All neutron and photon transport codes, including ANISN and MCNP, are being converted from the NIST CYBER 205 computer to the new NIST Cray Y-MP Computer. The DETAN code for dosimetry analysis and miscellaneous smaller codes are already on the Cray. The MCNP and YSPEC codes will be operational by the end of FY 91.

Calculations of Transmission of Neutrons Through Iron Shells. There is a long-standing question regarding the accuracy of the inelastic cross section in iron used to calculate fast neutron gradients in thick steel. This is a critical issue for predicting the useful service life of power reactor pressure vessels. In preparation for a benchmark program of iron shell transmission measurements at NIST, a series of calculations of the transmission of neutrons from a point fission neutron source through spherical shells of iron have been performed. The endpoint of these benchmark measurements will be to assess the adequacy of recently revised inelastic cross sections for iron.

Two-Component Room-Retum Model. Accurate calibration of neutron personnel instruments requires a correction for the effect of neutrons reflected from the walls of the calibration room. The current model for making this correction, derived from reflection in a spherical cavity, predicts a constant fluence of room-return neutrons over the volume of the room. Actual calibration rooms are usually rectangular parallelepipeds for which the room return fluence will vary with position. A modified room-return model has been devised which treats the first reflection as if it were from a plane slab, and the second and higher orders of reflection according to the original spherically symmetric model. The model for first reflection establishes a variation with position. The two-component model agrees well with Monte Carlo calculations and with experiment.

NIST/Westinghouse Cooperative Agreement for Measurement Assurance. Measurement assurance activities for Westinghouse radiometric (activation foil) and Solid State Track Recorder (SSTR) dosimetry continues. NIST is especially interested in problems with reliable masses for SSTR fissionable deposits that are in the nano-gram to pico-gram range, and which were developed by Westinghouse Industrial Technology Center.

SSTR Ultralight Mass Determination. Mass determinations require NIST provide known fluences to the ultra-lightweight SSTRs and Westinghouse measure their response and deduce masses. The irradiations are carried out in the ${ }^{235} \mathrm{U}$ Cavity Fission Source at the NIST Reactor, to an accuracy of about $2.5 \%(1 \sigma)$.

High $\mathrm{T}_{\mathrm{c}}$. The structures of a variety of high critical temperature $\left(\mathrm{Hi}-\mathrm{T}_{\mathrm{C}}\right)$ superconducting materials are being developed and studied at NIST. One material containing [B-Pb-Sr-CuO] may have properties that are dependent upon the state of the $\mathrm{CuO}$. The current density that this material can sustain is a function of the mobility of the microscopic magnetic flux vortices. Speculation that atomic defects may effectively trap the vortices is being tested. Use has been made of the NIST ${ }^{235} \mathrm{U}$ neutron fission spectrum irradiation facility to introduce controlled amounts of displaced atoms (i.e., defects) in the material by performing certified fluence 
irradiations, which are free of lower-energy neutrons that cause complicating neutron capture transmutations.

\section{IRRADIATION AND CALIBRATION FACILITIES}

Well-characterized neutron fields, built and maintained as permanent irradiation facilities, provide certified fluences of pure fission neutrons, sub-MeV distributions, monoenergetic keV beams, and thermal neutrons. Passive and active detectors are exposed in these neutron fields for response calibrations, for cross section measurements, and for the investigation of new measurement techniques. A multipurpose fission rate measurement capability is centered around the NIST "go anywhere" double fission chambers and the NIST set of fissionable isotope mass standards (FIMS). The Manganous Sulfate Bath is the primary neutron source strength calibration facility for the United States. Absolute neutron fluences for all fission-neutron-driven standard neutron fields at NIST are derived from source strength calibrations at this facility.

Design and Construction of the Materials Dosimetry Reference Facility (MDRF). A new, highintensity reference neutron field for reactor dosimetry, designed and constructed by NIST, will be operated at the University of Michigan 2MW Research Reactor. Certified fast-neutron fluence irradiations and related validation experiments, traceable to NIST, are to be performed in support of neutron dosimetry for the nuclear power and metallurgical-test communities.

The development of this benchmark facility is a natural extension of the long-term NIST program to develop standard neutron fields for measurement assurance applications in materials dosimetry, and the testing of new dosimetry detectors and techniques. The primary user of this irradiation facility will be industry and government organizations that have major responsibilities to assess the integrity of high-risk nuclear power reactor components and more generally to establish the data base that describes radiation damage in steel.

The MDRF complements existing fission neutron standard fields at NIST by providing a tenfold increase in fast-neutron fluence, a much larger irradiation volume with modest flux gradients, and a neutron spectrum rich in intermediate-energy neutrons. For the latter, the MDRF offers two spectrum options by operating with or without a boron-10 filter. A number of detector response characteristics and methods of dosimetry interpretation can be investigated with this choice.

Certification of the neutron fluence for dosimetry calibration and performance validation irradiations will be established on the basis of neutron fluence transfer from the NIST Fission Neutron Irradiation Facilities. It is anticipated that the neutron fluence above $1 \mathrm{MeV}$ will be specified to an uncertainty better than $10 \%$. Specification of the total neutron fluence will be more uncertain because of a much greater dependence on calculation.

Main features of the neutron spectra are the mild departure from a fission spectrum in the $\mathrm{MeV}$ energy range, the relaxation into a $1 / \mathrm{E}$ spectrum below $1 \mathrm{keV}$ for the MDRF without the boron-10 filter, and the cut-off in the $\mathrm{keV}$ range with the filter. 
A thorough characterization of the neutron spectrum will come from a combined interpretation of 2-d neutron transport calculations and benchmarked reaction rate measurements with threshold and low-energy detectors. A special feature of the spectrum tailored with a boron-10 filter will be the determination of the boron-10 thickness by means of a neutron transmission measurement in the $2 \mathrm{keV}$ filtered beam at NIST. The effective nuclear thickness obtained in this way removes all or most of the uncertainty in boron-10 enrichment, powder density in the thimble, and the absolute cross section scale for neutron absorption.

Activation detector calibrations planned for the MDRF will serve on-going and planned steel irradiations by Materials Engineering Associates and by ORNL at the U. Michigan Reactor, pressure vessel dosimetry contracts at the Westinghouse Nuclear Technology Division, and surveillance capsule backfitting and cavity dosimetry projects at B\&W. Expected dosimetry measurement assurance requirements proposed by the Nuclear Regulatory Commission may be conveniently and inexpensively served by the MDRF.

Continued development and calibration of Solid State Track Recorders (SSTRs), a dosimetry detector of great promise for reactor pressure vessel damage monitoring, will be substantially enhanced by the availability of the MDRF. A new generation of fission dosimeters in the form of paired uranium detectors (PUDS), sintered wires, and encapsulated beads can also be investigated and validated in the two component neutron fields of the MDRF.

Examples of attractive research opportunities are: (l) the iron inelastic scattering cross section discrepancy, crucial for the pressure vessel embrittlement uproar; (2) establishing $\mathrm{Nb}\left(\mathrm{n}, \mathrm{n}^{\prime}\right)$ activation as a practical main-line reactor dosimetry detector; and (3) determining proper corrections for subthreshold fission in Np, U234, and $\mathrm{U} 236$.

Calculations for the MDRF. The design of the MDRF required scoping calculations to explore the sensitivity of fluence intensity and spectrum to variations in design parameters. Accordingly, four types of 1-d neutron transport calculations were performed with the ANISN discrete ordinates code to simulate the actual cylindrical configuration. The first was a study of the spectrum at the center of an iron slab in water near the core of the reactor as a function of iron

thickness. The second was a comparison of spectra in slab and cylinder configurations. "The third calculation used the output spectrum from the slab calculation as input to the exterior cylindrical surface of the detector configuration. Finally, we studied the effect of a cylindrical sleeve of ${ }^{10} \mathrm{~B}$ on the fluence spectrum at the center of the cylindrical array. Results were adequate to decide upon a final configuration and proceed with the final design.

\section{COLD NEUTRON PHYSICS AND METROLOGY}

Two instrumental positions at the CNRF have been designated as experimental stations for investigations in an area of research which has come to be known as "Fundamental Neutron Physics." This work includes measurements of basic neutron properties, tests of fundamental symmetries of nature as well as investigations involving advanced methods in neutron optics. An additional program in advanced methods for neutron flux determination will have implications in neutron dosimetry, analytical chemistry, and nuclear physics. One instrumental position (on NG-7) will be on a monochromated beam, devoted to neutron interferometry. The other position 
(on NG-6) will be a full flux end position. It is currently devoted to studies of weak interaction physics.

Design and construction work on the neutron interferometer position has focused primarily on the implementation of a sophisticated seismic and vibrational isolation system. Neutron interferometers are exceptionally sensitive to external noise sources. The seismic isolation will consist of a cascaded series of sensitive passive isolation elements which will allow the use of an entirely new class of neutron interferometer employing separated perfect crystals as optical elements. This work is a collaboration with the University of Missouri, the University of Vienna (Austria) and the University of Melbourne (Australia).

The end position is currently in use for a variety of investigations aimed at providing a better understanding of neutron beta decay. A major effort involves the measurement of the neutron lifetime. This measurement involves two steps. First the decay rate of free neutrons in a cold beam must be measured. New apparatus has been built to carry out both of these measurements. Two novel highly accurate neutron flux monitors were installed on NG-6 in September 1991 and are being intercompared at the time of writing. In the early spring of 1992 the new neutron decay detector will be installed. Other experiments under development include a search for time reversal non-invariance and investigations into quark-quark weak interactions.

The neutron decay investigations are being carried out in collaboration with a variety of external institutions including The Central Bureau of Nuclear Measurements (Belgium), Los Alamos National Laboratory, Harvard University, University of Michigan, The Scottish Universities Research and Reactor Center (U. K.), Argonne National Laboratory and the University of California (Berkeley). 
Outputs/Interactions 


\section{PUBLICATIONS \\ Reactor Radiation Division}

An, M.; Lu, C.; Prince, E.; Tolimier, R., "Fast Fourier Transforms for Space Groups Containing Rotation Axes of Order Three and Higher", Acta Crystallogr., Sec. A (in press).

An, M.; Lu, C.; Prince, E.; Tolimieri, R., "Fast Fourier Transform Algorithms for Real and Symmetric Data", Acta Crystallogr., Sec. A (in press).

Anderson, I. S.; Berk, N. F.; Rush, J. J.; Udovic, T. J.; Bames, R. G.; Magerl, A.; Richter, D., "Reply to the Comment by Kadaro and Kiefl", Phys. Rev. Lett. 66, 2415 (1991).

Ankner, J. F., "Profile Refinement in Reflectivity and Grazing Angle Diffraction", in Proceedings of the Second International Conference on Surface X-ray and Neutron Scattering, edited by H. Zabel and I. K. Robinson, (Springer-Verlag, New York, 1991) in press.

Ankner, J. F。; Majkrzak, C. F。; Neumann, D. A.; Matheny A.; Flynn, C. P., "Polarized Neutrons Grazing-Angle Diffraction", Physica B (in press).

Ankner, J. F.; Majkrzak, C. F.; Neumann, D. A.; Matheny, A.; Flynn, C. P., "Reflectivity and Grazing Angle Diffraction of Polarized Neutrons", in Magnetic Thin Films, Multilayers and Surfaces, edited by S. P. Parkin Mater. Res. Soc. Symp. Proc., Vol. 231, (Materials Research Society, Pittsburgh, 1991), in press.

Bashir-Hashemi, A.; Ammon, H. L.; Choi, C. S., "Chemistry and Structure of Phenylcubanes", J. Org. Chem. 55, 416 (1990).

Beach, R. S.; Borchers, J. A.; Erwin, R. W.; Matheny, A.; Flynn, C. P.; Rhyne, J. J.; Salamon, M. B., "Effects of Epitaxial Strain in Er/Lu Thin Films", J. Appl. Phys. $\underline{69}$, 4535 (1991).

Beach, R. S.; Borchers, J. A.; Erwin, R. W.; Flynn, C. P.; Matheny, A.; Rhyne, J. J.; Salamon, M. B., "Magnetic Order in Dy/Lu Superlattices", J. Mag. \& Magn. Mater. (in press).

Berk, N. F., "Scattering Properties of the Leveled Wave Model of Random Morphologies", Phys. Rev. A. (in press).

Berk, N. F.; Anderson, I. S.; Rush, J. J.; Udovic, T. J.; Barnes, R. G.; Magerl, A., "Rapid Low Temperature "Hopping" of Hydrogen in a Pure Metal: The $\mathrm{ScH}_{\mathrm{x}}$ System", Phys. Rev. Lett. 65, 1439 (1990). 
Berk, N. F.; Rush, J. J.; Udovic, T. J.; Anderson, I. S., "Anomalous Hydrogen Dynamics in Rare Earth Materials", Internal. Conf. on Hydrogen-Metal Systems, J. Less-Common Met. (in press).

Borchers, J. A.; Salamon, M. B.; Erwin, R. W.; Rhyne, J. J.; Du, R. R.; Flynn, C. P., "Structural and Magnetic Properties of Er Thin Films and $\mathrm{Er} / \mathrm{Y}$ Superlattices: Magnetoelastic Effects", Phys. Rev. B 43, 3123 (1991).

Borchers, J. A.; Salamon, M. B.; Erwin, R. W.; Rhyne, J. J.; Nieuwenhuys, G. J.; Du, R. R.; Flynn, C. P.; Beach, R. S., "Structural and Magnetic Properties of Er Thin Films and Er/Y Superlattices: Modification of the Commensurate Spin States", Phys. Rev. B (in press).

Cannelli, G.; Cantelli, R.; Cordero, F.; Trequattrini, F.; Anderson, I. S.; Rush, J. J., "H Tunneling and Trapping by Y by Anelastic Relaxation Measurements", Phys. Rev. Lett. (in press).

Cao, G.; Yuen, Tan; Pernambuco-Wise, P.; Crow, J. E.; O'Reilly, J. W.; Kuric, M. V.; Guetin, R. P.; Rosov, N.; Lynn, J. W., "Thermodynamic and Magnetic Properties of the Tetravalent Rare Earth Perovskite System $\mathrm{BaPrO}_{3}$ " J. Appl. Phys. (in press).

Cappelletti, R. L.; Copley, J.R.D.; Kamitakahara, W. A.; Li, Fang; Lannin, J. S.; Ramage, D., "Neutron Measurements of Intramolecular Vibrational Modes in $\mathrm{C}_{60}$," Phys. Rev. Lett. 66, 3264 (1991).

Casella, R. C., "Nonlocal Phase Shifts Induced by Static Electric Fields in Neutron Interferometers When the Path-Enclosed Charge Vanishes", Phys. Rev. Lett. 65, 2217 (1990).

Casella, R. C., "A Theoretical Model for the Tunneling-Gap Anisotropy Observed in Layered Copper-Oxide High-Temperature Superconductors", Solid State Comm. 78, 377 (1991).

Cava, R. J.; Santoro, A.; Krajewski, J. J.; Fleming, R. M.; Waszczak. J. V.; Peck Jr., W. F.; Marsh, P., "The Crystal Structure of the $60 \mathrm{~K}$ Superconductor $\mathrm{La}_{1.6} \mathrm{Sr}_{9.4} \mathrm{CaCu}_{2} \mathrm{O}_{6+}$ ", Physica $C$ (in press).

Cieplak, M. Z.; Xiao, G.; Bakhshai, A; Artymowicz, D.; Bryden, W.; Chien, C. L.; Stalick, J. K.; Rhyne, J. J., "Incorporation of Gold Into $\mathrm{YBa}_{2} \mathrm{Cu}_{3} \mathrm{O}_{7}$ : Structure and $\mathrm{T}_{\mathrm{c}}$ Enhancement," Phys. Rev. B (in press).

Clinton, T. W.; Lynn, J. W., "Magnetic Ordering of Er in Powder and Single Crystals of $\mathrm{ErBa}_{2} \mathrm{Cu}_{3} \mathrm{O}_{7}$," Physica C $\underline{174}, 487$ (1991).

Clinton, T. W.; Lynn, J. W.; Liu, J. Z.; Jia, Y. X.; Shelton, R. N., "Magnetic Order of Dy in $\mathrm{DyBa}_{2} \mathrm{Cu}_{3} \mathrm{O}_{7}$," J. Appl. Phys. (in press). 
Collins, D. M.; Prince, E., "Exponential Density: Exact Fitting of Structure Moduli by Entropy Maximization", in Crystallographic Computing V: From Chemistry to Biology, edited by D. Moras, A. D. Podjarny, J. C. Thierry (Oxford University Press, 1991), p. 308.

Copley, J. R. D., "Acceptance Diagram Analysis of the Performance of Vertically Curved Neutron Monochromators," Nucl. Instrum. \& Methods in Phys. Res. A $\underline{301}$, 191 (1991).

Copley, J. R. D., "Monte Carlo Calculation of Multiple Scattering Effects in Thermal Neutron Scattering Experiments: Modification to Spherical Geometry", Computer Phys. Comm. (in press).

Copley, J. R. D., "Transmission Properties of a Counter-Rotating Pair of Disk Choppers", Nucl. Instrum. and Methods in Phys. Res. A $\underline{303}, 332$ (1991).

Copley, J. R. D.; Mildner, D. F. R., "Simulation and Analysis of the Transmission Properties of Curved-Straight Neutron Guide System", Nucl. Sci. and Eng. (in press).

Copley, J. R. D., "An Analytical Method to Characterize the Performance of Multiple Section Straight-Sided Neutron Guide Systems", Nucl. Instrum. and Methods in Phys. Res. A 287, 363 (1990).

Copley, J. R. D., "Scattering Effects Within an Absorbing Sphere Immersed in a Field of Neutrons", Nucl. Instrum. and Methods in Phys. Res. A (in press).

Dane, P. R.; Ferraro, M.; Ammon, H. L.; Choi, C. S., "Synthesis of 2, 2, 4, 4Tetranitroadamantane", J. Org. Chem. 포, 4459 (1990).

Depondt, Philippe; Neumann, D. A.; Trevino, S. F., "Neutron Scattering Study of Cs-ammonia Intercalated Graphite", Mater. Sci. Forum (in press).

Fan, Y.; Solin, S. A.; Kim, H.; Pinnavaia, T. J.; Neumann, D. A., "Elastic and Inelastic Neutron Scattering Study of Hydrogenated and Deuterated Trimethylammonium Pillared Vermiculite Clays", J. Chem. Phys. (in press).

Flynn, C. P.; Borchers, J. A.; Demers, R. T.; Du, R. R.; Dura, J. A.; Klein, M. V.; Kong, S.H.; Salamon, M. B.; Tsui, T. F.; Adavalli, S.; Zhu, X.; Zabel, H.; Cunningham, J. E.; Erwin, R. W.; Rhyne, J. J., "Growth and Properties of Superlattices with Antiferromagnetic Rare Earth", in Proceedings of the MRS International Meeting on Advanced Materials: in Multilayers, edited by Yamamoto Ryoichi, (Materials Research Society, Pittsburgh, 1990), p. 275.

Giebultowicz, T. M.; Klosowski, P.; Rhyne, J. J.; Samarth, N.; Luo, H.; Furdyna, J. K., "Incommensurate Antiferromagnetic Order in Strained Layer MnSe/ZnTe Superlattices", Physica B (in press). 
Giebultowicz, T. M., "Neutron Diffraction Studies of Magnetic Semiconductor Superlattices and Thin Films", XXth International School of Physics Semiconducting Compounds, JASZOWIEC, Poland, May 26-June 1, 1991, in press.

Gehring, P. M.; Tranquada, J. M.; Shirane, G.; Copley, J.R.D.; Erwin, R.; Sato, M.; Shamoto, S., "Magnetic Correlations and Energy Gap in Superconducting $\mathrm{YBa}_{2} \mathrm{Cu}_{3} \mathrm{O}_{6.6}$ with $\mathrm{T}_{\mathrm{c}}$ $=53 \mathrm{~K} "$, Phys. Rev. B 444, 2814 (1991).

Hammouda, B.; Schupp G.; Maglic, S., "QEGS from Polydimethylsiloxane in Benzene Solutions", J. Chem. Phys. 93, 5473 (1990).

Hammouda, B.; Briber, R.; Bauer, B., "SANS from PSD/PVME/PSH Ternary Polymer Blend", Polym. Comm., (in press).

Hammouda, B.; Nakatani, A.; Waldow, D.; Han, C. "SANS from PSD in DOP Solution under Shear", Macromolecules (in press).

Hammouda, B., "Structure Factor for Dendrimer Polymer Gels", J. Polym. Sci., Polym. Phys. (in press).

Hammouda, B., "SANS from Homogeneous Polymer Systems: A Unified Overview", Adv。 in Polym. Sci. (in press).

Harrison, W. T. A.; Gier, T. E.; Moran, K. L.; Nicol, J. M.; Eckert, J.; Stucky, G. D., "Structure and Properties of New Zeolite X-Type Zincophosphate and Berylliophosphate Molecular Sieves", Chem. Mater. $\underline{3}, 27$ (1991).

Hempelmann, R.; Richter, D.; Rush, J. J.; Rowe, J. M., "Hydrogen Site Distribution in the Alloy System $\mathrm{Nb}_{100 \mathrm{x}} \mathrm{V}_{\mathrm{x}} \mathrm{H}_{\mathrm{y}}$ Studied by Means of Neutron Vibrational Spectroscopy", J. Less-Common Met. (in press).

Kamitakahara, W. A.; Cappelletti, R. L.; Boolchand, P.; Halfpap, B.; Gompf, F.; Neumann, D. A.; Mutka, H., "Vibrational Densities of States and Network Rigidity in Chalcogenide Glasses", Phys. Rev. B 444, 94 (1991).

Karen, V. L.; Mighell, A. D., "Converse-Transformation Analysis", J. Appl. Cryst. (in press).

Karen, V. L.; Mighell, A. D., "NIST*LATTICE - A Program to Analyze Lattice Relationships" (Version of Spring 91). NIST Technical Note 1290. National Institute of Standards and Technology, US Department of Commerce (1990).

Kirchheim, R.; Kieninger, W.; Huang, X. Y.; Filipek, S. M.; Rush, J. J.; Udovic, T. J., "Hydrogen in Amorphous Ni-Zr and Ni-Ti Alloys", J. Less-Common Met. (in press).

Klosowski, P.; Giebultowicz, T. M.; Rhyne, J. J.; Samarth, N.; Luo, H.; Furdyna, J. K., "Antiferromagnetic Ordering in MnSe/ZnSe Multilayers", J. Appl. Phys. 69, 6109 (1991). 
Klosowski, P.; Giebultowicz, T. M.; Samarth, N.; Luo, H.; Furdyna, J. K.; Rhyne, J. J., "Investigation of ZnMnTe Weakly Diluted Magnetic Semiconductor", Physica B (in press).

Klosowski, P.; Giebultowicz, T. M.; Samarth, N.; Luo, H.; Furdyna, J. K.; Rhyne, J. J., "Magnetic Critical Phenomena in fcc Antiferromagnets--Role of Strain and Dimensionality", Proceedings of the International Conference on Magnetism, Edinburgh, 1991 (in press).

Krueger, S.; Long. G. G.; Black, D.; Minor, D.; Jemian, P. R.; Nieman, G. W.; Page, R. A., "Evolution of the Pore Size Distribution in Final Stage Sintering of Alumina Measured by Small-Angle X-Ray Scattering", J. Am. Ceramic Soc. (in press).

Krueger, S.; Chen, S.-H.; Hofrichter, J.; Nossal R., "Small Angle Neutron Scattering Studies of HbA in Concentrated Solutions", Biophys. J. $\underline{58}, 745$ (1991).

Krueger, S.; Long, G. G.; Page, R. A., "Characterization of the Densification of Alumina by Multiple Small-Angle Neutron Scattering", Acta Crystallogr. A 74, 282 (1991).

Layer, H. P.; Greene, J. L., "Elastic Deformation of a Monolithic Perfect Crystal Interferometer: Implications for Gravitational Phase Shift Experiments", Phys. Lett. A $\underline{155}, 450$ (1991).

Lewicki, A.; Schindler, A. I.; Furdyna, J. K.; Giebultowicz, T. M., "Magnetic Properties of Co-Based Diluted Magnetic Semiconductors", in Diluted Magnetic Semiconductors, edited by M. Jain, (World Scientific), in press.

Lindemuth, P.; Hammouda, B.; Venable, R., "SANS from TPB based Microemulsions", J. Phys. Chem. (in press).

Long, G. G.; Krueger, S.; Jemian, P. R.; Black, D. R.; Burdette, H. E.; Cline, J. P.; Gerhardt, R. A., "Small Angle Scattering Determination of the Microstructure of Porous Silica Precursor Bodies", J. Appl. Crystallogr. 23, 535 (1990).

Long, G. G.; Krueger, S.; Gerhardt, R. A.; Page, R. A., "Small Angle Neutron Scattering Characterization of Processing/Microstructure Relationships in the Sintering of Crystalline and Glassy Ceramics", J. Mat. Res. (in press).

Lynn, J. W.; Sumarlin, I. W.; Neumann, D. A.; Rush, J. J.; Peng, J. L.; Li, Z. Y., "Phonon Density of States and Superconductivity in $\mathrm{Nd}_{1.85} \mathrm{Ce}_{9.15} \mathrm{CuO}_{4}$ ", Phys. Rev. Lett. $\underline{66}, 919$ (1991).

Lynn, J. W., "Two-dimensional Behavior of the Rare Earth Ordering in Oxide Superconductors", J. Alloys and Compounds (in press).

Majkrzak, C. F., "Polarized Neutron Reflectometry", Physica B 173, 75 (1991). 
Majkrzak, C. F.; Felcher, G. P., "Neutron Scattering Studies of Surfaces and Interfaces", MRS Bulletin, XV(11), 65 (1990).

Majkrzak, C. F.; Kwo, J.; Hong, M.; Yafet, Y.; Gibbs, Doon; Chien, C. L.; Bohr, J., "Magnetic Rare Earth Superlattices", Adv. Phys. (in press).

Marezio, M.; Santoro, A.; Capponi, J. J.; Hewat, E. A.; Cava, R. J.; Beech, F., "Crystal Structure, Atomic Ordering and Charge Localization if $\operatorname{Pr}_{2} \mathrm{Sr}_{2} \mathrm{Y}_{1-\mathrm{x}} \mathrm{Ca}_{\mathrm{x}} \mathrm{Cu}_{3} \mathrm{O}_{8+8}(\mathrm{x}=\mathrm{O}$, $\delta=1.47) "$, Physica C $\underline{169}, 40$ (1990).

McKinnon, W. R.; Tselepis, E.; Tarascon, J. M.; Miceli, P. F.; Remschnig, K.; Hull, G. W.; Neumann, D. A.; Rhyne, J. J. "Weak Ferromagnetism and Canting in $\mathrm{BiPbSr}_{2} \mathrm{MnO}_{6}$ and $\mathrm{BiPbCa}_{2} \mathrm{MnO}_{6}$ ", Phys. Rev. B 41,4489 (1990).

Menelle, A.; Russell, T. P.; Anastasiadis; S. H.; Satija, S. K.; Majkrzak, C. F. "The Ordering of Thin Diblock Copolymer Films", Phys. Rev. Lett. (in press).

Mighell, A. D.; Karen, V. L., "NIST CRYSTAL DATA - A Data Base of Chemical, Physical and Crystallographic Data and the NIST/Sandia/ICDD Electron Diffraction Database" 1990 Versions. The Databases and search software are made available to the scientific community on CD-ROM, on magnetic tape, via scientific instruments and the CRYSTDAT on-line system.

Mildner, D.F.R.; Hammouda, B., "The Transmission of Curved Neutron Guides with NonPerfect Reflectivity", J. Appl. Crystal. (in press).

Mozer, B.; Bendersky, L. A.; Boettinger, W. J.; Rowe, R. G., "Neutron Powder Diffraction Study of the Orthorhombic $\mathrm{Ti}_{2} \mathrm{~A} 1 \mathrm{Nb}$ Phase", Scripta Metallur. 24, 2363 (1990).

Neumann, D. A., "Inelastic and Quasielastic Neutron Scattering Studies of Layer Silicates", in Neutron Scattering for Clay Mineral Investigation, edited by F. Ross (Clay Minerals Society, Bloomington), in press.

Nicol, J. M., "Chemisorbed Hydrogen and Hydrogenous Molecules", Spectrochimica Acta (in press).

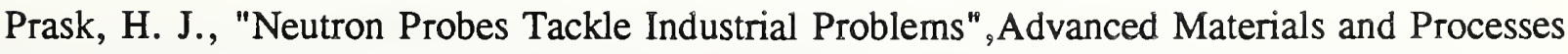
140, No. 3, September 1991, p. 26.

Prask, H. J.; Choi, C. S., "Residual Stress Characterization in Technological Samples", Proceedings of Practical Applications of Residual Stress Technology Conference, edited by C. Ruud, (Published by ASM International), in press.

Prask, H. J.; Choi, C. S., "Residual Stress Measurement in Armament-Related Components", Proceedings of NATO Advanced Workshop on Measurement of Residual and Applied Stress Using Neutron Diffraction, edited by M. Hutchings, (Oxford, 1991), in press. 
Prince, E., "Mathematical Aspects of Rietveld Refinement", in Proceedings of the International Workshop on the Rietveld Method, edited by R. A. Young, (Oxford University Press, Oxford, England), in press.

Rhyne, J. J.; Erwin, R. W.; Borchers, J. A.; Salamon, M. B.; Tsui, F; Du, R. R.; Flynn, C. P., "Magnetic Rare Earth Artificial Metallic Superlattices", in NATO Advance Study Institute on the Science and Technology of Nanostructured Magnetic Materials, edited by G. Prinz and G. Hadjipanayis, (Plenum Press, 1990), in press.

Rice, B. M.; Trevino, S. F., "An Intermolecular A-O Potential for Methyl Rotations in Solid Nitromethane", J. Chem. Phys. (in press).

Robertson, J. L., "Random Cluster Models for Icosahedral Phase Alloys", Proceedings of the International Workshop on Methods of Structural Analysis of Modulated Structures and Quasicrystals, (World Scientific Publishing), in press.

Rowe, J. M.; Prask, H. J., "Status of Research Reactor Instrumentation in the USA", Physica B 174,421 (1991).

Rowe, J. M.; Rorer, D. C., "Existing Cold Sources at U.S. Reactors", in International Workshop on Cold Neutron Research Sources, compiled by G. J. Russell and C. D. West (Los Alamos National Laboratory, Los Alamos, New Mexico, 1990), LA-12146-C Conference, p. 121.

Russell, T. P.; Menelle, A.; Anastasiadis, S. H.; Satija, S. K.; Majkrzak, C. F., "Unconventional Morphologies of Symmetric, Diblock Copolymers Due to Film Thickness Constraints", Macromolecules (in press).

Russell, T. P.; Menelle, A.; Hamilton, W. A.; Smith, G. S.; Satija, S. K.; Majkrzak, C. F., "The Width of Homopolymer Interfaces in the Presence of Symmetric Diblock Copolymers", Macromolecules (in press).

Salamon, M. B.; Beach, R. S.; Borchers, J. A.; Erwin, R. W.; Flynn, C. P.; Matheny, A.; Rhyne, J. J., "Magnetism of Rare-Earth/Y and Rare-Earth/Lu Superlattices and Films", Physica Scripta (in press).

Salamon, M. B.; Borchers, J.; Du, R.; Flynn, C. P.; Tsui, F.; Beach, R. S.; Erwin, R. W.; Rhyne, J. J. "Magnetic Properties of Epitaxial Metallic Superlattice", Physica Scripta T35, 163 (1991).

Samarth, N.; Klosowski, P.; Luo, H.; Giebultowicz, T. M.; Furdyna, J. K.; Rhyne, J. J.; Larson, B.; Otsuka, N., "Antiferromagnetism in MnSe/ZnSe Strained-Layer Superlattices, Phys. Rev. B 44 , 4701 (1991).

Santoro, A.; Beech, F.; Cava, R. J. "Models for Oxygen Ordering and Diffusion in $\mathrm{Ba}_{2} \mathrm{YCu}_{3} \mathrm{O}_{\mathrm{x}}$ and $\mathrm{Ba}_{2} \mathrm{YCu}_{3-\mathrm{x}} \mathrm{M}_{\mathrm{x}} \mathrm{O}_{\mathrm{y}}[\mathrm{M}=\mathrm{Fe}, \mathrm{Co}, \mathrm{Al}, \mathrm{Ga}]$, Proceedings of the 7th CIMTEC Meeting on Superconductors (in press). 
Santoro, A., "Defective Structures of $\mathrm{Ba}_{2} \mathrm{YCu}_{3} \mathrm{O}_{\mathrm{x}}$ and $\mathrm{Ba}_{2} \mathrm{YCu}_{3-\mathrm{y}} \mathrm{M}_{\mathrm{y}} \mathrm{O}_{\mathrm{z}}$, (M=Fe, Co, $\left.\mathrm{Al}, \mathrm{Ga}, \ldots\right)$," in Chemistry of Superconducting Materials, edited by T. A. Vanderah (Noyes Publications), in press.

Santoro, A., "Crystal Chemistry of Superconductors and Related Compounds," in Chemistry of Superconducting Materials, edited by T. A. Vanderah, (Noyes Publications), in press.

Sanyal, M. K.; Sinha, S. K.; Gibaud, A.; Satija, S. K.;Majkrzak, C. F.; Homma, H., "Specular and Diffuse Scattering Studies of Multilayer Interfaces", in Proceedings of the 2nd International Conference on Surface X-Ray and Neutron Scattering, edited by H. Zabel and I. K. Robinson, (Springer-Verlag, New York, 1991), in press.

Schroeder, J.; Hammouda, B.; Bubeck, R. A.; Chang, J. W., "SANS From Hot Stretched Polystyrene Revisited", J. Polym. Sci. (in press).

Schupp, G.; Hammouda, B.; Hsueh, C., "Quasielastic Gamma-ray Scattering from Pentadecane", Phys. Rev. A 41, 5610 (1990).

Sinha, S. K.; Sanyal M. K.; Gibaud, A.; Satija, S. K.; Majkrzak, C. F.; Homma, H., "The Characterization of Interface Roughness and Other Defects in Multilayers by X-Ray Scattering", NATO Advanced Study International Conference Proceeding, (Greece, June 1990), in press.

Sjolin, L.; Prince, E.; Svensson, L. A.; Gilliland, G. L., "Ab Initio Phase Determination for Xray Diffraction Data from Crystals of a Native Protein", Acta Crystallogr. A 47, 216 (1991).

Skanthakumar, S.; Lynn, J. W.; Peng J. L., "Antiferromagnetic Ordering of $\mathrm{Cu}$ in $\mathrm{Sm}_{2} \mathrm{CuO}_{4}$ ", J. Appl. Phys. $\underline{49}, 4866$ (1991).

Skanthakumar, S.; Lynn, J. W., "On the Crystal and Spin Structures $\mathrm{Nd}_{2} \mathrm{CuO} 4$ ", Physica $\mathrm{C} \underline{170}$, 175 (1990).

Skanthakumar, S.; Lynn, J. W., "Magnetic Order of $\mathrm{Cu}$ in $\mathrm{Nd}_{2-\mathrm{x}} \mathrm{Ce}_{\mathrm{x}} \mathrm{CuO}_{4}$ ", J. Magn. \& Magn. Mater. (in press).

Stalick, J. K.; Gotaas, J. A.; Cheng, S. F.; Cullen, J.; Clark, A. E., "Crystallographic and Magnetic Structure of $\mathrm{Pr}_{2} \mathrm{Fe}_{17} \mathrm{~N}_{2.8}$ ", Mater. Lett. (in press).

Straty, G. C.; Hanley, H. J. M.; Glinka, C. J., "Shearing Apparatus for Neutron Scattering Studies on Fluids: Preliminary Results for Colloidal Suspensions", J. Stat. Phys. $\underline{62}$, 1015 (1991).

Tsui, F.; Flynn, C. P.; Salamon, M. B.; Borchers, J. A.; Erwin, R. W.; Rhyne, J. J., "Layer Thickness Dependence of Anisotropic Coupling in Gd/Y Superlattices", J. Mag. \& Magn. Matls. (in press). 
Tsui, F.; Flynn, C. P.; Salamon, M. B.; Erwin, R. W.; Borchers, J.; Rhyne, J. J., "Anisotropic Magnetic Behavior in Dy/Y Films and Superlattices", Phys. Rev. B 43, 13320 (1991).

Wada, N.; Kamitakahara, W. A., "Inelastic Neutron and Raman Scattering Studies of Muscovite and Vermiculite Layered Silicates", Phys. Rev. B 43, 286 (1991).

Wu, W. L.; Satija, S. K.; Majkrzak, C. F., "Neutron Reflectivity Study at a Polymer-Solid Interface", Polymer Communications (in press).

Yoo, J. N.; Sperling, L. H.; Glinka, C. J.; Klein, A. "Characterization of Film Formation from Polystyrene Latex Particles via SANS 2. High Molecular Weight", Macromolecules 24 , 2868 (1991).

Yu, S. C.; Lynn, J. W.; Rhyne, J. J.; Fish, G. E., "Low Temperature Magnetization and Magnetic Excitations in Amorphous $\mathrm{Fe}_{78} \mathrm{~B}_{13} \mathrm{Si}_{9}$ ", J. Mag. \& Magn. Mater. 97, 286 (1991).

Zhang, Huai; Lynn, J. W.; Morris, D. E., "Two-Dimensional Bilayer Magnetic Order of Dy Ions in $\mathrm{Dy}_{2} \mathrm{Ba}_{4} \mathrm{Cu}_{7} \mathrm{O}_{15} "$, J. Mag. and Magn. Mater. (in press). 


\section{TECHINICAL AND PROFESSIONAL COMMITTEE PARTICIPATION AND LEADERSHIP}

American Crystallographic Association

A.I.P. Crystal Data Committee, A. D. Mighell, ACA Representative

American National Standards Insitute

N-17 Research Reactors, Reactor Physics, and Shielding

T. M. Raby, Chairman, J. Torrence, Alternate Member

American Nuclear Society

-Standards Steering Committee, T. M. Raby, Member

-Standards Subcommittee, ANS-15, Operations of Research Reactors

T. M. Raby, Member

-Working Groups ANS-15.1, ANS-15.11

T. M. Raby, Chairman, J. F. Torrence Member

Basic Energy Sciences Advisory Committee (DOE)

J. M. Rowe, Vice Chairman

Brookhaven National Lab. Neutron Scattering Facility Scheduling Committee

J. J. Rush, Member

French National Center for Scientific Research (C.N.R.S.), Louis Neel Laboratory, Scientific Advisory Panel, J. J. Rhyne, Member

Intense Pulsed Neutron Source (Argonne) and Los Alamos Neutron Scattering Center, Program Review Committee, J. J. Rhyne, Member

International Conference on Surface X-ray and Neutron Scattering, Germany, 1991

International Advisory Committee, C. F. Majkrzak, Member

International Collaboration on Advanced Neutron Sources

Advisory Committee, J. M. Rowe, Member

International Meeting on Hydrogen in Metals, Upsala, Sweden, June 1992

Advisory Committee, J. J. Rush, Member

International Union of Crystallography

-Commission on Crystallographic Nomenclature, Subcommittee on Statistical Descriptions in

Crystallography, E. Prince, Member

-Commission on Journals, E. Prince, Member

-Data Commission, Alan Mighell, Member

JCDDS--International Centre for Diffraction Data

-Crystal Data Management Board, A. D. Mighell, Member

-Crystal Data Committee, A. D. Mighell, Member 
-Database Subcommittee, A. D. Mighell, J. K. Stallick, Members

-Electron Diffraction Subcommittee, A. D. Mighell, Member

-Neturon Diffraction Commission, E. Prince, Member

Journal of Applied Crystallography

E. Prince, Co-Editor

Journal of Magnetism and Magnetic Materials

J. J. Rhyne, Member

Los Alamos Neutron Scattering Center

Scientific Advisory Committee, J. M. Rowe, Chairman

National Organization for Test, Research and Training Reactors

T. M. Raby, Member of Executive Committee and Past Chairman

J. F. Torrence, Member and past Co-Chairman.

National Steering Committee for the Advanced Neutron Source

J. J. Rush, Executive Committee

Neutron Optical Devices and Applications, SPIE, San Diego, CA

C. F. Majkrzak, Conference Chair, J.R.D. Copley. Co-Chair

Program Advisory Committee for High Flux Beam Reactor at Brookhaven National Laboratory

C. F. Majkrzak, Member 


\section{Industrial and Academic Interactions}

As a national center for the development and application of neutron methods in condensed matter and materials science, chemical analysis and radiation standards, the Reactor Radiation Division and other NIST organizations have direct interactions and cooperative programs with 63 universities, 32 industrial and 40 foreign laboratories. Some examples of the many interactions of the Neutron Scattering Group are:

- $\quad$ An agreement is in place between NIST and Exxon Research and Development Corporation to jointly develop and operate a world-class small angle neutron scattering spectrometer at the NIST cold neutron source. This facility was commissioned and began operation this past year. Cooperative research efforts include work on wetting in microporous media and micellar systems and research on new polymers.

- Construction is well underway on the new NIST/NSF Center for High Resolution Neutron Scattering at the CNRF which will offer U.S. scientists access to world-class capabilities in high resolution small angle neutron scattering studies of materials microstructure and in very high resolution spectroscopy of condensed materials using polarized neutron beams. The first instrument, the SANS, is scheduled for operation in the spring of 1992.

- An intense cooperative research effort continues with several groups at AT\&T Bell Laboratories on the systematic studies of the structure and properties of new high-temperature superconductor compounds. Other superconductor research efforts involve collaborative work with Dupont, SRI and a number of universities.

- A PRT agreement has been established with IBM for the development and application of neutron reflectometry for unique studies of surface and interfacial structure of polymer films, liquids and other materials. This research has thus far led to the best results worldwide in neutron studies of polymer surfaces.

- The Reactor Radiation Division's Crystal Data Center is engaged in a number of interactive links including joint development and distribution to U.S. science and industry of evaluated crystal data with the International Center for Diffraction Data. The Data Center also has long-term agreements in place with crystal data programs in Canada, Great Britain, and Germany to jointly develop and share critical data on the structure of materials. An expansion of database systems into electron diffraction and microscopy has recently been achieved in cooperation with Sandia. Several instrument companies have already integrated this new data base into their products.

- An agreement is continuing with Sandia National Laboratory for collaborative development of instrumentation and opportunities in cold neutron spectroscopy, including provision of incremental funding by Sandia. Areas of joint research interest include microporous chemical media, aerogels and new glassy materials. 
- The Neutron Scattering Group has in place wide collaborative research with the University of California (Santa Barbara) involving neutron inelastic scattering, neutron diffraction, and SANS studies of catalysts, non-linear optical materials, and radiation damage.

- Extensive cooperative research efforts with the Physics Department and Materials Research Laboratory at the University of Illinois have continued during the past year including neutron diffraction studies of magnetic multilayer materials and studies of shear induced structural changes in colloidal systems. Joint efforts also continue to investigate the use of near-grazing angle neutron diffraction in surface structure studies, including magnetic diffraction on thin films.

- $\quad$ The Reactor Radiation Division has a long-term cooperative research program with the Department of Physics of the University of Maryland. Under this program RRD staff are engaged with Maryland scientists in joint research on magnetic materials, superconductors and catalysts. Some of this research is carried out jointly with scientists from industrial labs.

A joint research effort has been established with Penn State University for the study of the structures, phase transformations and excitations of simple gases adsorbed in microporous glasses using neutron diffraction and inelastic scattering.

The University of Minnesota, through its Center for Interfacial Engineering (CIE), has joined with the Reactor Radiation Division in the development and use of two high-resolution instruments at the Cold Neutron Research Facility (CNRF): a 30-meter Cold Neutron Small-Angle Scattering Spectrometer and a Cold Neutron Reflectometer. The CIE, with its thirty affiliate or sponsoring companies, will use these instruments with NIST for the elucidation of the structure and microstructure of polymers and other materials, as well as surface and interfacial structure and interactions.

The Center for Materials Science and Engineering at the MIT is participating with the Reactor Radiation Division in the development and use of a new 32detector, high resolution powder neutron diffractometer for materials research at the NIST Reactor. The new instrument will be a world-class instrument with state-of-the-art capabilities in resolution, versatility, and data collection efficiency. Of particular initial interest in the collaborative program are structural studies of graphite intercalation compounds, fast-ion conductors, and advanced ceramics.

- A new cooperative research effort was established this past year with the Physics Department at Johns Hopkins University for joint research on new magnetic materials, including low dimensional magnetic systems. As part of this agreement Hopkins is providing funding and concept design support for joint development of a cold neutron triple axis spectrometer at the CNRF. 


\section{$\underline{\text { Associated Activities }}$}

During the past year staff and visiting scientists in the Reactor Radiation Division delivered 49 invited lectures in the U.S. and abroad. Group members were invited participants in a number of workshops in the neutron field. Neutron Group scientists also continue to share several NATO grants with French and German colleagues in different areas of condensed matter physics. Joint research continues with ORNL and two small companies in the development of supermirrors. Two highly successful workshops on high resolution cold neutron spectroscopy and on SANS and reflectometry, were held this past year, attracting 150 scientists from industries, universities and government. 

NIST-114A

(REV. 3-90)
U.S. DEPARTMENT OF COMMERCE NATIONAL INSTITUTE OF STANDARDS AND TECHNOLOGY

BIBLIOGRAPHIC DATA SHEET
1. PUBLCATION OR AEPORT NUMBEA NISTIR 4698

2. PERFORMINO ORGANIZATION REPORT NUMBEA

3. PUBLCATION DATE

Nowember 1991

4. TITLE AND SUBTITLE

Technical Activities 1991

Materials Science and Engineering Laboratory

Reactor Radiation

5. AUTHOA(S)

H. J. Prask, editor

6. PERFORMING ORGANIZATION (IF JOINT OR OTHER THAN MIST, SEE INSTRUCTIONS)

U.S. DEPARTMENT OF COMMEACE

MATIOMAL INSTITUTE OF STANDARDS AND TECHNOLOCY

GATTHEASBUAG, MD 2089

7. CONTRACT/GRANT MUMBEA

8. TYPE OF REPOAT AND PEAIOD COVERED

9. SPONSORINO ORQANZATION MAME AND COMPLETE ADDAESS (STREET, CTY, STATE, ZP)

10. SUPPLEMENTAAY MOTES

11. ABSTRACT (A 200-WORD OA LESS FACTUAL SUMMARY OF MOST SIONIFICANT INFORMATION. IF DOCUMENT INCLUDES A SIGNIFICANT BIBLOGAAPHY OR ITERATUAE SUAVEY, MENTION IT HERE)

This report summarizes all those programs which depend on the NIST reactor. It covers the period from October 1, 1991 through September 30, 1991. The programs include the application of neutron methods to the characterization of materials, neutron standards, trace analysis by neutron activation analysis, neutron depth profiling, nondestructive evaluation and the prodcution of radioisotopes.

12. KEY WOADS (6 TO 12 ENTRIES; ALPHABETICAL ORDEA; CAPITALZE ONLY PROPER NAMES; AND SEPARATE KEY WORDS BY SEMICOLONS) activation analysis; crystal structure; diffraction; isotopes; molecular dynamics; neutron; neutron radiography; nondestructive evaluation; nuclear reactor; radiation

\section{AVAILABIUTY}

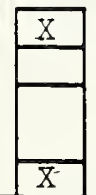

UNUMITED

FOR OFFICIAL DISTAIBUTION. DO NOT RELEASE TO MATIONAL TECHNICAL INFORMATION SERVICE (NTIS).

ORDER FAOM SUPEAINTENDENT OF DOCUMENTS, U.S. GOVERNMENT PRINTING OFFICE, WASHINOTON, DC 20402.

ORDER FAOM NATIONAL TECHMICAL IMFORMATION SERVICE (NTIS), SPAIMGFIED, VA 22161.

14. NUMBEA OF PAINTED PAGES

$$
64
$$

15. PRICE

A04 


$$
-
$$


